\title{
Generalización de la gestión por procesos como plataforma de trabajo de apoyo a la mejora de organizaciones de salud ${ }^{*}$
}

\section{Generalization of business process management as a framework supporting health care improvement}

\section{Generalização da gestão por processos como uma plataforma de trabalho de apoio à melhoria de organizações de saúde}

Fecha de recepción: 27-01-16 Fecha de aceptación: 06-09-16 Disponible en línea: 30-11-16 doi:10.11144/Javeriana.rgyps15-31.ggpp

Cómo citar este artículo:

Hernández-Nariño A, Delgado-Landa A, Marqués-León M, Nogueira-Rivera D, Medina-León A, Negrín-Sosa E. Generalización de la gestión por procesos como plataforma de trabajo de apoyo a la mejora de organizaciones de salud. Rev. Gerenc. Polít. Salud. 2016; 15(31): 66-87. http://dx.doi. org/10.11144/Javeriana.rgyps15-31.ggpp

\author{
Arialys Hernández-Nariño** \\ Adriana Delgado-Landa*** \\ Maylín Marqués-León**** \\ Dianelys Nogueira-Rivera***** \\ Alberto Medina-León****** \\ Ernesto Negrín-Sosa*******
}

\footnotetext{
Artículo resultado de una investigación financiada por la Universidad de Matanzas Camilo Cienfuegos, Cuba. Fecha de inicio del proyecto: noviembre del 2009: fecha de finalización: diciembre del 2013.

** Doctora en Ciencias Técnicas, profesora auxiliar del Departamento de Ciencia y Técnica de la Facultad de Ciencias Médicas de la Universidad de Ciencias Médicas “Dr. Juan Guiteras Gener”, Matanzas. Cuba. Dirección: Laborde final \# 6305 entre San Isidro e Isabel 1ra. Reparto Versalles. Matanzas. Cuba. CP: 10400. Correo electrónico: arialys. hernandez@gmail.com, investigaciones.mtz@infomed.sld.cu

**** Máster en Administración de Empresas, mención Dirección. Profesora asistente del Departamento de Matemática Aplicada de la Facultad de Ingenierías de la Universidad de Matanzas "Camilo Cienfuegos". Cuba.

***** Doctora en Ciencias Técnicas, profesora auxiliar del Departamento de Técnicas de Dirección de la Facultad de Ciencias Económicas e Informática de la Universidad de Matanzas "Camilo Cienfuegos". Cuba. Correo electrónico: maylin.marques@umcc.cu

****** Doctora en Ciencias Técnicas, profesora titular del Departamento de Ingeniería Industrial de la Facultad de Ciencias Económicas e Informática de la Universidad de Matanzas "Camilo Cienfuegos". Cuba.

******* Doctor en Ciencias Técnicas, profesor titular de la Oficina de Intercambio Académico de la Universidad de Matanzas "Camilo Cienfuegos". Cuba.

******** Doctor en Ciencias Técnicas, profesor titular del Departamento de Técnicas de Dirección de la Facultad de Ciencias Económicas e Informática de la Universidad de Matanzas "Camilo Cienfuegos". Cuba.
} 


\title{
Generalización de la gestión por procesos como plataforma de trabajo de apoyo a la mejora de organizaciones de salud ${ }^{*}$
}

\section{Generalization of business process management as a framework supporting health care improvement}

\section{Generalização da gestão por processos como uma plataforma de trabalho de apoio à melhoria de organizações de saúde}

Fecha de recepción: 27-01-16 Fecha de aceptación: 06-09-16 Disponible en línea: 30-11-16 doi:10.11144/Javeriana.rgyps15-31.ggpp

Cómo citar este artículo:

Hernández-Nariño A, Delgado-Landa A, Marqués-León M, Nogueira-Rivera D, Medina-León A, Negrín-Sosa E. Generalización de la gestión por procesos como plataforma de trabajo de apoyo a la mejora de organizaciones de salud. Rev. Gerenc. Polít. Salud. 2016; 15(31): 66-87. http://dx.doi. org/10.11144/Javeriana.rgyps15-31.ggpp

\author{
Arialys Hernández-Nariño** \\ Adriana Delgado-Landa*** \\ Maylín Marqués-León**** \\ Dianelys Nogueira-Rivera***** \\ Alberto Medina-León****** \\ Ernesto Negrín-Sosa*******
}

\footnotetext{
Artículo resultado de una investigación financiada por la Universidad de Matanzas Camilo Cienfuegos, Cuba. Fecha de inicio del proyecto: noviembre del 2009: fecha de finalización: diciembre del 2013.

** Doctora en Ciencias Técnicas, profesora auxiliar del Departamento de Ciencia y Técnica de la Facultad de Ciencias Médicas de la Universidad de Ciencias Médicas “Dr. Juan Guiteras Gener”, Matanzas. Cuba. Dirección: Laborde final \# 6305 entre San Isidro e Isabel 1ra. Reparto Versalles. Matanzas. Cuba. CP: 10400. Correo electrónico: arialys. hernandez@gmail.com, investigaciones.mtz@infomed.sld.cu

**** Máster en Administración de Empresas, mención Dirección. Profesora asistente del Departamento de Matemática Aplicada de la Facultad de Ingenierías de la Universidad de Matanzas "Camilo Cienfuegos". Cuba.

***** Doctora en Ciencias Técnicas, profesora auxiliar del Departamento de Técnicas de Dirección de la Facultad de Ciencias Económicas e Informática de la Universidad de Matanzas "Camilo Cienfuegos". Cuba. Correo electrónico: maylin.marques@umcc.cu

****** Doctora en Ciencias Técnicas, profesora titular del Departamento de Ingeniería Industrial de la Facultad de Ciencias Económicas e Informática de la Universidad de Matanzas "Camilo Cienfuegos". Cuba.

******* Doctor en Ciencias Técnicas, profesor titular de la Oficina de Intercambio Académico de la Universidad de Matanzas "Camilo Cienfuegos". Cuba.

******** Doctor en Ciencias Técnicas, profesor titular del Departamento de Técnicas de Dirección de la Facultad de Ciencias Económicas e Informática de la Universidad de Matanzas "Camilo Cienfuegos". Cuba.
} 


\section{Resumen}

El Sistema Nacional de Salud Cubano se plantea como reto el perfeccionamiento de la gestión de sus instituciones, para lo cual considera objetivos medulares: fomentar la creatividad y la innovación, impulsar la formación permanente, buscar la eficiencia, estudiar buenas prácticas internacionales y propiciar una constante evaluación de los procesos. Estos propósitos son comunes a enfoques gerenciales frecuentemente adoptados por las organizaciones que buscan calidad, eficiencia, eficacia y mejor servicio al cliente. Este trabajo busca ilustrar los resultados de experiencias de gestión por procesos como plataforma de trabajo que impulsa la mejora de los servicios de salud. Para ello muestra la inserción de un procedimiento, resultado del estudio bibliográfico de setenta propuestas metodológicas. Se toman cinco hospitales de una provincia cubana para probar la utilidad de los instrumentos y luego se aprecian los avances en el servicio y el desempeño hospitalario, así como la extensión del estudio a otros hospitales del territorio.

Palabras clave: gerencia; procesos; mejoramiento; servicios de salud

\section{Abstract}

Cuban National System faces an important challenge, which is to consolidate the improvement programs of their institutions; consequently, there are considered key objectives like: fostering creativity and innovation; promoting continuous training; and ensuring the efficiency seeking, the application of best practices and permanent processes evaluation. These objectives are commonly assumed when organizations adopted managerial approaches based on quality, efficiency, effectiveness and service to clients. Hence, this paper shows the results of experiences in business process management, being conceived as a work setting of improvement in health institutions. To seek such goal, it is conducted a bibliography study of 70 methodological procedures, resulting in a new approach that is applied to five hospitals in a Cuban province in order to prove its efficacy for performance improvement, which is illustrated by progress being obtained in service and processes functioning with consequent extension to other hospital of the province.

Keywords: management; processes; improvement; health care services

\section{Resumo}

O Sistema Nacional de Saúde cubano confronta o desafio de melhorar a gestão das suas instituições, para o qual são considerados como objetivos centrais a promoção da criatividade e da inovação, a promoção da aprendizagem permanente, a busca da eficiência, o estudo das melhores práticas internacionais e uma avaliação constante dos processos. Estes efeitos são comuns a abordagens de gestão, muitas vezes adoptadas pelas organizações que buscam qualidade, eficiência, eficácia e melhor atendimento ao cliente. Este trabalho procura ilustrar os resultados de experiências de gestão de processos como uma plataforma de trabalho que impulsiona a melhoria dos serviços de saúde, traves da inserção de um procedimento, resultado da revisão de literatura de setenta propostas metodológicas. Cinco hospitais de uma província cubana são tomados para testar a utilidade dos instrumentos, depois sao avaliados os avances no serviço e o desempenho hospitalar, e finalmente é apresentada a extensão do estudo para outros hospitais da região.

Palavras-chave: gestão; processos, melhoria; serviços de saúde 


\section{Introducción}

Una revisión bibliográfica de textos científicos, investigaciones y libros sobre gestión por procesos y BPM, control de gestión y administración en salud, publicados entre 1985 y 2013, en países como España, Estados Unidos, Brasil, Cuba y otras regiones de Latinoamérica, revela antecedentes importantes en el desarrollo de la gestión hospitalaria, como a continuación se revela.

En el mundo el sector de salud constituye uno de los empleadores más importantes, al ocupar entre el 7 y el $13 \%$ de la mano de obra. Entre el 2000 y el 2006, los gastos aumentaron su participación en el Producto Interno Bruto (PIB), al pasar del 8 al $8.7 \%$ (1); estos datos demuestran el interés que debe prestarse a su gestión.

El servicio hospitalario tiene peculiaridades como: el cliente es el paciente y su acompañante; este no siempre paga el producto o servicio que recibe (característica propia de hospitales públicos, como los pertenecientes al sistema de salud cubano), pero sí evalúa la calidad percibida, y percibe mayor calidad del servicio cuanto más tiempo se invierta en su atención; es el médico quien decide la demanda de servicios, tratamientos y atenciones hospitalarias; $y$, como plantean Bonafont y Casasín (2), existe gran variabilidad en la atención de salud y la práctica clínica.

Las particularidades mencionadas distinguen la gestión de instituciones de salud, por lo que es importante considerar aquellos elementos que los diferencian de otros sistemas, en virtud de adaptar apropiadamente las herramientas que se utilizan.

De acuerdo con Claveranne y Pascal (3), la gestión por procesos puede suavizar estas inconveniencias, a partir del reconocimiento y el análisis de todos los procesos, para a partir de su descripción y características mejorarlos o rediseñarlos. Esto significaría orientar los servicios hospitalarios y funciones dentro de un hospital, desde una perspectiva de procesos. La inserción de este enfoque fue el resultado de una evolución en la gestión hospitalaria.

En la evolución de la gestión hospitalaria, los directivos comenzaron a asumir retos como: los pacientes desempeñan el rol de demandantes con capacidad de optar entre alternativas terapéuticas, profesionales y centros asistenciales; la sociedad promueve estrategias de participación de la comunidad en los asuntos del sector, de transparencia en la toma de decisiones y exige garantías de calidad del servicio, sin que se causen largas estadías hospitalarias o prácticas no correctas; se fomenta la motivación del personal de salud por la excelencia en la asistencia, la investigación y la docencia; y el logro de la eficiencia en la utilización de recursos (4).

Estas instituciones desarrollan iniciativas encaminadas a la planificación y la programación de operaciones (5-8), la gestión del componente humano y del conocimiento y las competencias de los profesionales (9). Comienzan a introducir las tecnologías de la información y las comunicaciones (10), a implementar plataformas logísticas para lograr suministros rápidos de material a los almacenes hospitalarios, lo que propicia estrategias de just-in-time, de reducción de suministros, de mejora de la gestión de sus procesos y la introducción de modelos de gestión clínica $(2,11,12)$.

La gestión y mejora de los procesos y la introducción de modelos de gestión clínica, se benefician de experiencias en: gestión de riesgos (13), análisis de puntos críticos de control (14), utilización del benchmarking $(15,16)$, planificación y programación de operaciones (17) y análisis basados en las 
características clínicas de los pacientes, también conocido como Case Mix $(18,19)$.

El desarrollo del enfoque de procesos en la gestión de organizaciones de salud $(3,20)$, como en el mundo empresarial, ha evolucionado hacia la aplicación de una teoría en franco ascenso: el Business Process Management (BPM), que se considera una herramienta competitiva para las organizaciones $(21,22)$, a la que los gerentes apelan, generalmente, cuando buscan el rediseño de procesos para mejorar la eficiencia operativa, incrementar la conformidad de los productos o servicios o propiciar la innovación (23).

Existen dos tendencias principales, relacionadas en su inicio con esta herramienta: la gestión total de la calidad (TQM) y la reingeniería de procesos (BPR) (24,25); y este vínculo se basa en la idea de que tienen como elemento central de análisis a los procesos (26).

Según Krafzig et al. (27) el BPM se aborda desde dos perspectivas: el contexto del negocio, asociado frecuentemente con iniciativas relativas a la calidad (6 sigma, TQM) o a la propia gestión por procesos (ABC, BSC), y según la perspectiva tecnológica se encuentran soluciones para el modelado de procesos o gestión de flujos (27).

Su evolución transita por el desarrollo de conceptos como la alineación de las operaciones con las prioridades estratégicas, consideradas claves para la competitividad, unidas a otro concepto subyacente e igual de importante: la participación del personal de trabajo (28). Previamente, Zairi (28) había definido al BPM como un enfoque dependiente de elementos estratégicos y operativos, del uso de técnicas y herramientas modernas, el compromiso de los empleados $\mathrm{y}$, esencialmente, de una base horizontal que garantizaría una satisfacción más óptima de los requerimientos del cliente.
En consecuencia, existen seis elementos esenciales en el BPM: la alineación estratégica, la gobernanza, los métodos, la tecnología de información, las personas y la cultura (29).

Estos aspectos han conducido a estudios de factores críticos para el éxito de la implementación de un BPM. Ravesteyn (30) proporciona cinco dimensiones, como son: a) comprensión del BPM (involucra el concepto, la alineación estratégica y el compromiso de la gerencia); b) comprensión del proceso (técnicas de modelado de la calidad, calidad de las fuentes de datos); c) gestión de la integridad del proceso (integralidad de los servicios e integración de las aplicaciones disponibles a través de los servicios); d) calidad de la gestión de proyectos (gestión del cambio y participación del personal); y e) definición de métricas de desempeño (disponibilidad de los datos y organización de la optimización continua) (31).

La aplicación del BPM en salud se asocia a la necesidad de elevar la calidad (32) y la eficiencia en estas organizaciones, con base en el hecho de que los administradores de salud se encuentran bajo grandes presiones para reducir costos, a la vez que se mejore la calidad de la atención (33). A continuación, se enuncian algunos ejemplos que validan esta consideración:

- Introducir el BPM en una instalación médica de Estados Unidos generó mejorías significativas en calidad, eficiencia y seguridad de los pacientes, a partir de la reducción de los tiempos de prevención de infecciones y la disminución de los errores humanos, debido a la informatización de los reportes de infecciones (33).

- La inserción de un enfoque de BPM basado en diseño de patrones y estándares genera beneficios en: el análisis 
de formas más eficientes y eficaces de realizar un proceso; la definición de requerimientos y estándares para el proceso; la asignación de benchmarks para el patrón de comportamiento, con la posibilidad de auditar las áreas de negocio con base en dichos benchmarks; y en el aprendizaje del personal (34).

- Kolker (35) aborda la aplicación del BPM a procesos médicos, a los flujos de pacientes y vías clínicas, para evaluar el efecto de la duración de la estancia del paciente en un departamento de emergencia.

- Bertolini (36) realizó un estudio con un área de neurocirugía de sala del hospital de Parma. Allí definió las etapas de un Business Process Reengineering (BPR), acompañadas de la determinación de los objetivos estratégicos, un levantamiento del mapa de procesos, la representación gráfica de los procesos críticos aplicando la metodología AS IS, así como el rediseño de procesos ya existentes y nuevos.

- El diseño de guías clínicas, herramientas para el aseguramiento de la calidad, optimización de procesos, benchmarking y análisis de costos, en un contexto de BPM, se asocia con la reducción de las complicaciones hospitalarias y la mejora de la documentación sin afectar la duración de la estancia y los costos (37).

Por su parte, el sector de salud cubano, durante muchos años, no había sido favorecido por la utilización de herramientas gerenciales. Primero, la situación financiera del país produjo grandes afectaciones en los servicios de salud, al imposibilitar la obtención de importantes recursos y tecnologías; luego este no había sido un campo ampliamente explotado en cuanto a investigaciones se refiere.
A la luz de estas ideas, desarrollar el enfoque de procesos en organizaciones de salud cubanas representa una línea de trabajo de gran potencial, pues brinda respuestas a algunas de las proyecciones de este sector en la búsqueda de la excelencia.-

\section{Materiales y métodos}

La consulta bibliográfica reflejó el desarrollo de procedimientos metodológicos (setenta), que valoran catorce variables presentes en la gestión y en la mejora. Mediante el método de los clúster se identificaron grupos de procedimientos con características distintivas en el análisis implícito o explícito de un $50 \%$ de las variables; en otro caso, la inclusión parcial de solo el $14 \%$ de estas variables, e incluso la no correspondencia de varios procedimientos con las variables establecidas. De ellos resaltan seis propuestas concebidas para el sector de la salud con similares atributos a aquellos provenientes del sector empresarial.

Como resultado se desarrolló un procedimiento metodológico para la gestión por procesos (figura 1), basado en las fases comunes de la gestión por procesos (análisis, mejora y seguimiento y control) y en su perfeccionamiento y ajuste a las características de las instituciones de salud cubanas, cuatro hospitales y un hogar de ancianos. Dicha metodología está compuesta de cuatro fases, configuradas de la siguiente forma:

Para la fase I (caracterización y diagnóstico) se constituye el equipo de trabajo, de tal manera que se garantice la representatividad de las áreas de resultados clave del hospital. Posteriormente, la caracterización y la clasificación constituyen la vía para familiarizarse con la actividad esencial de la organización y tener una idea inicial de hacia dónde debe apuntar la gestión de sus procesos; para ello se utilizan trece variables adaptadas de 


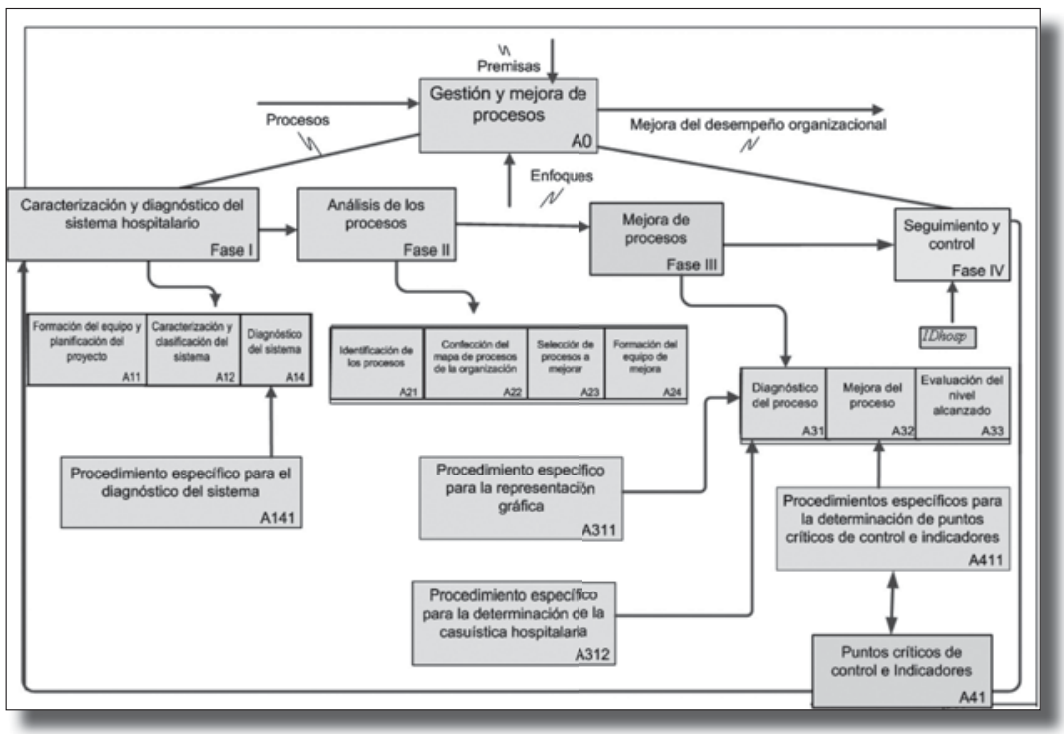

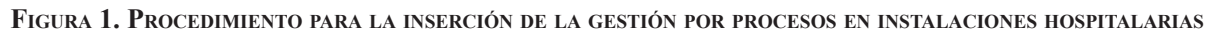
Fuente: (53)

Fernández Sánchez (38) y expuestas en Hernández Nariño et al. (39). Esta fase culmina con el diagnóstico del sistema, sustentado en el triángulo de los servicios propuesto por Schroeder (40).

En la fase II (análisis de los procesos), primero se clasifican los procesos en operativos o clave, estratégicos y de apoyo, para su ilustración en el mapa de procesos. Luego se identifican los procesos relevantes por el método del coeficiente de concordancia de Kendall; de ellos se seleccionan aquellos prioritarios para la mejora, considerando criterios como su alineación a los objetivos estratégicos, su impacto en la satisfacción de los pacientes, su variabilidad o la probabilidad de obtener beneficios a corto plazo, tal como proponen Claveranne y Pascal (3), Nogueira Rivera et al. (41) y Amozarrain (42), y valiéndose de la técnica de proceso analítico de jerarquía (43).

En la fase III (mejora de los procesos) se describe el proceso objeto de estudio, a través de técnicas de representación gráfica como los diagramas As Is (44), los mapas IDEF0 (45) o la ficha de procesos, la cual registra aspectos de interés para la gestión y el control. Después se detectaron las oportunidades de mejora con el uso de herramientas como el análisis de la casuística hospitalaria. Para identificar los principales grupos de pacientes y su influencia en el diseño del servicio (18), sirvió de apoyo el uso de procedimientos de muestreo de historias clínicas durante cuatro años, para así agrupar los pacientes según métodos como GDR (en hospitales clínico-quirúrgicos, ginecobstétricos y generales) y RUG (para hogar de ancianos); evaluación de entradas y proveedores para evaluar cuáles son las entradas del proceso, qué requerimientos deben cumplir y qué evaluación se le confiere a cada proveedor en el cumplimiento de esos requerimientos; (46) análisis de valor añadido, para determinar el aporte de valor de las actividades del proceso a través de su incidencia en los objetivos, su contribución a las expectativas de los grupos de interés, su impacto en las características de calidad y si esta actividad constituye un momento 
de la verdad o no $(47,48)$; y determinación de los tiempos (48), para visualizar reservas de eficiencia en su uso, con la aplicación de la distribución Beta para la determinación de tres tiempos (pesimista, optimista y más probable), considerando la variabilidad de los procesos estudiados, como propone Sánchez Lara (49).

En la fase IV (seguimiento y control) se diseña un índice integral para evaluar el desempeño de los procesos hospitalarios (IDhosp). Para su construcción fue útil una revisión de la literatura sobre indicadores de evaluación de la actividad hospitalaria $(50,51)$. En una revisión documental se identificaron los indicadores principales en la gestión del desempeño de las instituciones hospitalarias tomadas como caso de estudio, se seleccionaron aquellos que caracterizan la gestión del hospital. Con ayuda de expertos previamente elegidos de acuerdo a la metodología de Frías Jiménez et al. (52) y con ayuda del método de proceso analítico de jerarquía (AHP), se definió el peso relativo de los indicadores componentes de un índice integral para la evaluación de la gestión hospitalaria. Finalmente, considerando los tipos de hospitales estudiados, se normalizó la evaluación del comportamiento de cada indicador.

Posteriormente, los resultados obtenidos en un grupo reducido de instituciones de salud se generalizaron hasta abarcar, primero, siete hospitales entre los años 2008 y 2011 —de ellos cuatro de tipo clínico-quirúrgico, una institución ginecobstétrica, una policlínica, un hogar de ancianos $(53,54)$, y luego se replicaron las aplicaciones en un hospital general en el período 2012-2013 (55), todos ubicados en el tercer nivel de acuerdo al número de camas que poseen (entre cero y trescientas camas).

\section{Resultados}

Las experiencias en la aplicación de las herramientas planteadas se centraron en instituciones de salud del territorio matancero, que responden a tres clasificaciones fundamentales: clínico-quirúrgicos, ginecobstétrico y hogar de ancianos. Dicha clasificación incide en el universo de pacientes, los tipos de patologías que atienden estos hospitales y los servicios que ofrecen; lo cual es de interés en los análisis subsiguientes, por cuanto determina el ajuste y la adaptación de las herramientas utilizadas (39).

Las aplicaciones obtenidas se sintetizan a continuación.

\section{Fase I. Diagnóstico de la organización}

El diagnóstico reveló, de manera general, la necesidad de potenciar el enfoque de procesos y aplicar herramientas gerenciales para resolver problemas relativos a la organización de las actividades asistenciales y de apoyo, el aseguramiento de insumos y los sistemas de control de gestión de las organizaciones hospitalarias estudiadas.

\section{Fase II. Análisis de los procesos}

El primer paso en esta fase fue la identificación de los procesos que integran la organización (tabla 1), a partir de agrupar todas las actividades que se realizan, relacionadas con la asistencia (procesos operativos), el aseguramiento de los procesos operativos (procesos de apoyo) y la conducción estratégica (procesos estratégicos).

La representación del mapa de procesos del hospital permitió hacerse una idea clara de los procesos que representan la institución, reconocer aquellos de impacto directo en el paciente y sus acompañantes y que deben 
Tabla 1. Resumen de PRocesos identificados en los hospitales ObJETo de ESTUdio fundamental

\begin{tabular}{|c|c|c|c|}
\hline $\begin{array}{l}\text { Hospitales clínico- } \\
\text { quirúrgicos (1 y 2) }\end{array}$ & $\begin{array}{l}\text { Hospital } \\
\text { ginecobstétrico }\end{array}$ & Hospital general & Hogar de ancianos \\
\hline $\begin{array}{l}\text { Gobierno } \\
\text { hospitalario }\end{array}$ & Gestión económica & Gestión de calidad & $\begin{array}{l}\text { Gestión de la } \\
\text { Dirección }\end{array}$ \\
\hline Gestión económica & Gestión de calidad & Gestión económica & Admisión al hogar \\
\hline Gestión de calidad & $\begin{array}{l}\text { Gestión del capital } \\
\text { humano }\end{array}$ & $\begin{array}{l}\text { Gestión del capital } \\
\text { humano }\end{array}$ & $\begin{array}{l}\text { Servicios técnico } \\
\text { asistenciales }\end{array}$ \\
\hline $\begin{array}{l}\text { Gestión del } \\
\text { conocimiento }\end{array}$ & $\begin{array}{l}\text { Gestión del } \\
\text { conocimiento }\end{array}$ & $\begin{array}{l}\text { Hospitalización } \\
\text { (servicio quirúrgico } \\
\text { lectivo y electivo, } \\
\text { ginecobstetricia) }\end{array}$ & $\begin{array}{l}\text { Servicio de } \\
\text { enfermería }\end{array}$ \\
\hline $\begin{array}{l}\text { Gestión del capital } \\
\text { humano }\end{array}$ & $\begin{array}{l}\text { Hospitalización } \\
\text { (neonatología, } \\
\text { ginecología, parto) }\end{array}$ & $\begin{array}{l}\text { Atención a } \\
\text { urgencias y } \\
\text { emergencias }\end{array}$ & Gestión Económica \\
\hline $\begin{array}{l}\text { Hospitalización } \\
\text { (servicios clínicos, } \\
\text { quirúrgicos) }\end{array}$ & $\begin{array}{l}\text { Atención a } \\
\text { urgencias y } \\
\text { emergencias }\end{array}$ & Medios diagnósticos & $\begin{array}{l}\text { Gestión de recursos } \\
\text { humanos }\end{array}$ \\
\hline $\begin{array}{l}\text { Urgencias y } \\
\text { emergencias }\end{array}$ & Consulta externa & Consulta externa & $\begin{array}{l}\text { Gestión de servicios } \\
\text { generales }\end{array}$ \\
\hline Servicios externos & Medios diagnósticos & Proceso docente & $\begin{array}{l}\text { Servicios de } \\
\text { alojamiento }\end{array}$ \\
\hline Apoyo asistencial & $\begin{array}{l}\text { Gestión de la } \\
\text { información }\end{array}$ & $\begin{array}{l}\text { Gestión de la } \\
\text { información }\end{array}$ & $\begin{array}{l}\text { Gestión de } \\
\text { mantenimiento y } \\
\text { energía }\end{array}$ \\
\hline $\begin{array}{l}\text { Gestión del sistema } \\
\text { informativo }\end{array}$ & Abastecimiento & Gestión logística & $\begin{array}{l}\text { Gestión de } \\
\text { almacenes }\end{array}$ \\
\hline Transporte & Mantenimiento & $\begin{array}{l}\text { Producción y } \\
\text { servicios }\end{array}$ & \\
\hline Intendencia & Servicios generales & & \\
\hline $\begin{array}{l}\text { Abastecimiento } \\
\text { médico }\end{array}$ & Esterilización & & \\
\hline \multicolumn{4}{|l|}{ Servicios generales } \\
\hline \multicolumn{4}{|l|}{$\begin{array}{l}\text { Construcción y } \\
\text { alojamiento }\end{array}$} \\
\hline \multicolumn{4}{|l|}{ Electromedicina } \\
\hline \multicolumn{4}{|l|}{ Ingeniería } \\
\hline $\begin{array}{l}\text { Central de } \\
\text { esterilización }\end{array}$ & & & \\
\hline
\end{tabular}

Fuente: elaboración propia 


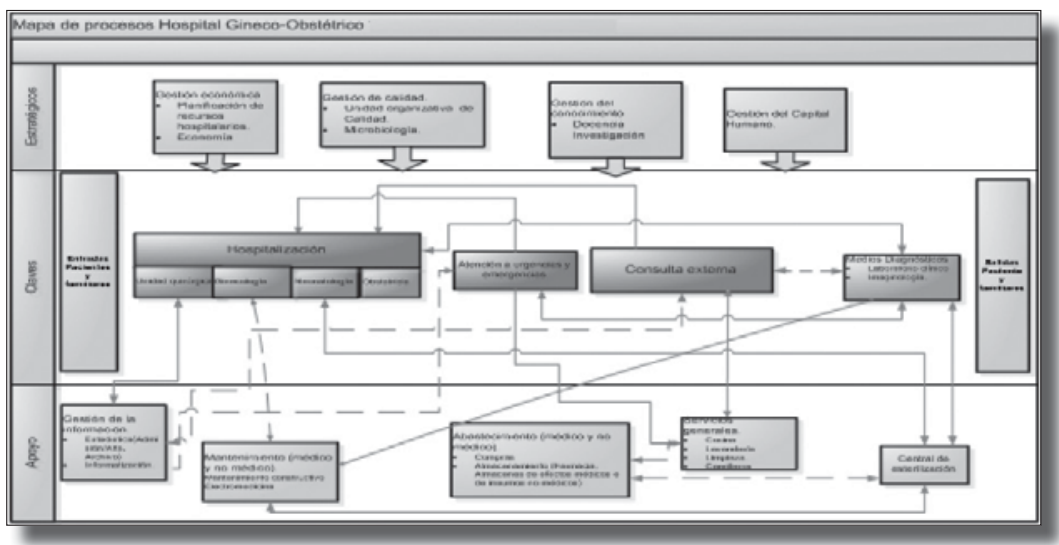

Figura 2. MAPa de procesos hospital ginecobstétrico

Fuente: (53)

tributar al cumplimiento de la misión definida, así como las principales interrelaciones entre cada uno de ellos, lo cual tiene un papel importante en el análisis y mejoramiento de los procesos (figura 2).

En el hospital ginecobstétrico, los procesos que, tal como plantea la ISO, resultan claves para la organización, son: hospitalización (unidad quirúrgica, neonatología, ginecología y obstetricia), atención a urgencias y emergencia, consulta externa y medios diagnósticos. En ejercicio de planificación estratégica ${ }^{1}$ estas resultaron ser las áreas de resultados clave para el cumplimiento de la misión.

La aplicación del principio de que la gestión por procesos se centra en la mejora de aquellos claves para el desempeño de la organización, condujo a la selección de los procesos críticos para la mejora. En este sentido se tuvieron en cuenta dos aspectos:

1 Conducido por un grupo de profesores de los departamentos de Técnicas de Dirección e Ingeniería Industrial de la Facultad Industrial-Economía de la Universidad de Matanzas en el marco de la consultoría realizada en dicho hospital ginecobstétrico. Los autores de este trabajo forman parte de ese grupo consultor.
- Los criterios para la selección de los procesos. Los equipos de trabajo coincidieron en considerar importantes, además de los criterios propuestos por Amozarrain (42) y Nogueira Rivera (56) (impacto en los objetivos estratégicos, impacto en el cliente y éxito a corto plazo), la variabilidad (hospital clínico quirúrgico 1, hospital clínico quirúrgico Il, hospital ginecobstétrico y hogar de ancianos), la repetitividad y el peso económico (hospital ginecobstétrico).

- El análisis del nivel de importancia que el equipo de trabajo le concede a cada criterio. Para asignarle el peso relativo se utilizó el método AHP (proceso analítico de jerarquía) (figura 3).

De estos análisis se seleccionaron, generalmente, como procesos críticos para la mejora: hospitalización y alojamiento, medios diagnósticos, urgencias y emergencias y relativos a servicios de enfermería.

\section{Fase III. Mejora de procesos}

En esta fase se utiliza, de forma gradual, un grupo de herramientas para buscar oportunidades de mejora, como son: diagramas 


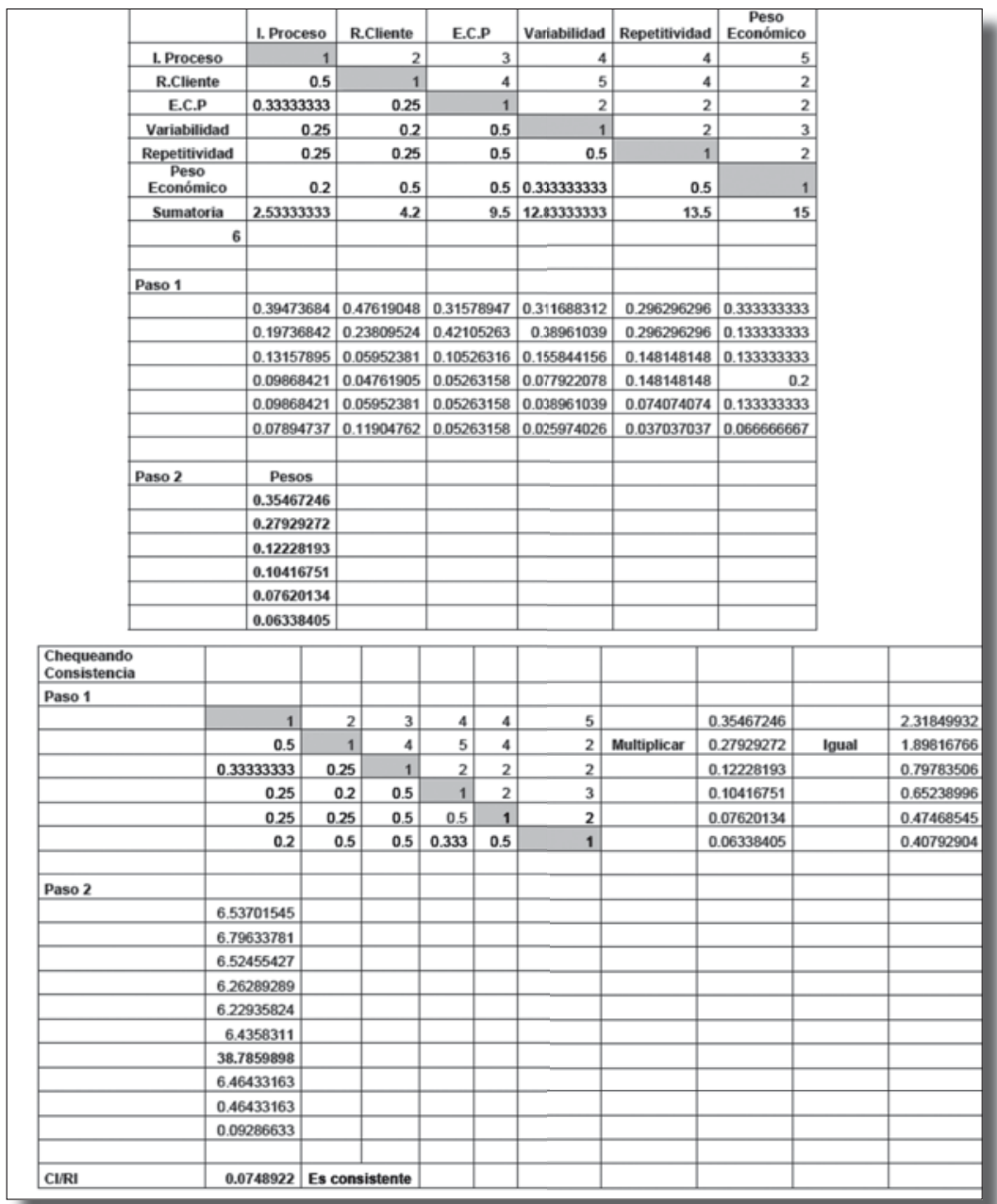

Figura 3. Aplicación del método AHP en el hospital ginecobstétrico

Fuente: (53)

As Is y técnicas IDEF0, fichas de procesos, análisis de valor añadido, estudios de los tiempos de ejecución, evaluación del nivel de servicio, análisis de riesgos e identificación de la casuística hospitalaria.

La descripción del proceso de medicina interna en el hospital clínico-quirúrgico, a partir de un diagrama As Is (figura 4) y su ficha de proceso (figura 5), permitió caracterizarlo y clasificarlo en proceso de alto contacto con el paciente, de relativamente baja intensidad de la mano de obra y alta adaptación, lo que lo define como taller de servicio.

El análisis del valor añadido de las actividades, utilizando como criterios: los objetivos del proceso, los momentos de verdad, las características de calidad y las expectativas de los grupos de interés del proceso, se enfocó en valorar en qué medida cada actividad, identificada en el diagrama As Is, cumple con los criterios enunciados. 
Arialys Hernández-Nariño • Adriana Delgado-Landa $・$ Maylín Marqués-León • Dianelys Nogueira-Rivera • Alberto Medina-León • Ernesto Negrín-Sosa

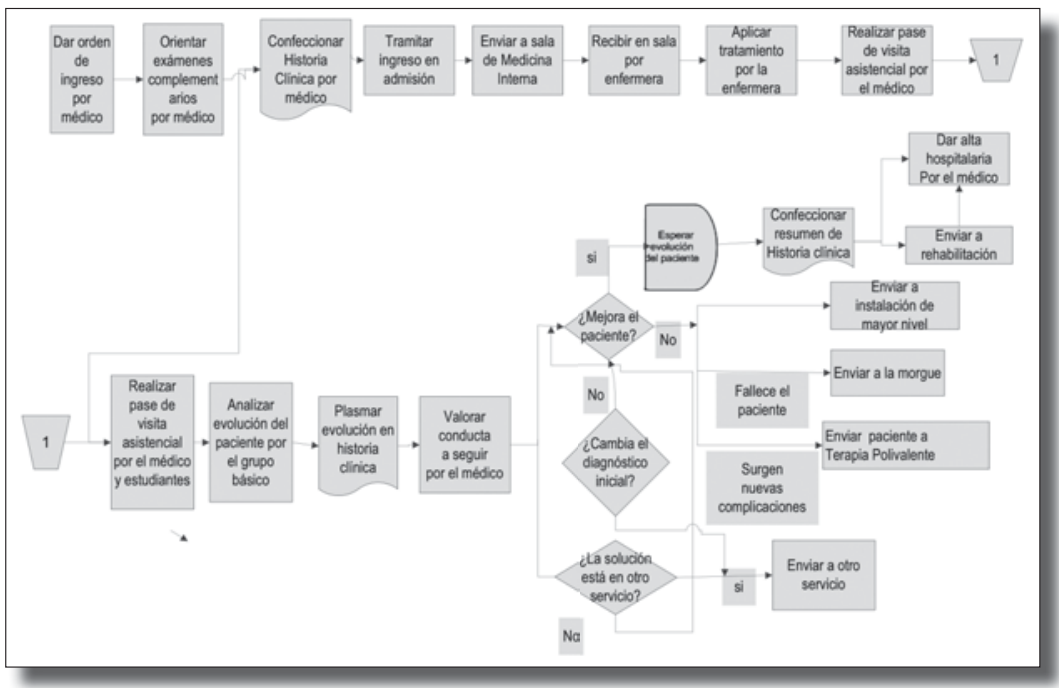

Figura 4. Diagrama As Is de un proceso de medicina interna

Fuente: (53)

Responsable: Jefe del Servicio Medicina Interna $\quad$ Tipo de Proceso: Operativo Finalidad del Proceso: Estudiar y prevenir las enfermedades clínicas y quirúrgicas, ungentes y no urgentes de todo el organismo. Es el encargado de la definición diagnóstica y terapéutica de las afecciones que le corresponden como especialista y una vez concluido el estudio se encarga del seguimiento yio revisión.

Objetivos: Prestar atención a los casos hospitalizados y realizar estudio para determinar enfermedades.

Proveedores: Abastecimiento General, Cocina- Comedor, Vestuario, Lavandería, Central de Esterilización, Laboratorio Fitofármacos, Electromedicina, Medios diagnóstic 08 , Mantenimiento, Servicios Generales, P atolo gía, Farmacia.

Clientes Pacientes ingresados y acompañantes, pacientes de consulta externa, sery icio de urgencias, Atención primaria de salud, Policlínicos de: Canimar, Guanábana, Playa, Reparto Reynol Garcia, Reparto 2 de Diciembre y Universidad de Matanzas "Camilo Clenfuegos".

Entradas: pacientes, medicamentos, material e instrumental gastable y estéril, médicos, enfermeras, técnicos, historia clínica, hojas de cargo.

Salidas: Paciente tratado, paciente con tratamiento, Resumen de H. Clínica, Material desechable o no estéril.

Grupos de interés: personal médico y paramédico, proveedores, estudiantes de medicina y técnicos medios, directivos.

Inicio del Proceso: examinar al paciente.

Fin del proceso: dar alta al paciente, trasladar al paciente a otro ho sp tal u otro servicio.

Actividades incluidas: recibir al paciente por el médico, registrar el caso en la hoja de cargo, examinar al paciente, orientar tratamiento inicial esperar por los resultados, dar orden de ingre so, cumplir las indicaciones médicas por la enfermera en sala, plasmar la evolución del caso en la historia clínica, esperar la recuperación del paciente, dar alta o remisión médica al paciente.

Procedimientos: protoc olos clínico-terapéutic os

Indicadores: promedio de camas, mortalidad, correlación IngresosiEgresos satisfacción de paciente, indice ocupacional, indice de ausentismo, promedio estadia índice de rotación, intervalo de sustitución, índice de reingreso, tasa de infecciones.

Variables de control: dias camas, dias pacientes, costos unitarios, ingresos, egresos, fallecidos Registros: historias clínic as, registros de infecciones, registros de pacientes, registro de complementarios, libro de entrega de guardia, actas de discusiones de casos complejos, manual de indicadores.

Inspecciones: auditoría mensual y semestral, control de enfermería, circulo de calidad, vigilancia epidemiológica

Procesos relacionados: Medios Diagnósticos, Abastecimiento de Material, Áseguramiento Técnico, Gestión del Conocimiento, Gestión de la Calidad, Consulta Externa, Urgencia y Emergencia

Actividades relacionadas con otros procesos: recibir al paciente (urgente o electivo), indicar pruebas diagnósticas, orientar exámenes complementarios, confeccionar historia clínica para dar seguimiento por consulta externa.

\section{seguimiento porconsulta externa.}

Figura 5. Ficha del PROCESO MEdicina INTERNa 
Así se determinó, por un lado, que el $21 \%$ de las actividades poseen un aporte de valor débil, el $44 \%$ medio y el $35 \%$ fuerte; por otro lado, que la contribución específica a cada criterio denotó que se debe trabajar en la alineación del proceso y sus actividades a los objetivos estratégicos y a las características de calidad; y finalmente, que es preciso estudiar posibilidades de mejoramiento en cuanto a los tiempos de operación, la gestión basada en las características clínicas de los pacientes, la prevención basada en los riesgos y el nivel de servicio al paciente y los acompañantes.

La caracterización de la casuística del proceso, a partir del muestreo de historias clínicas correspondientes a los años 2004 y 2005, permitió conformar las categorías diagnósticas mayores (CDM) y valorar el porcentaje de pacientes que se hospitalizaron de acuerdo a igual diagnóstico. La tabla 2 refleja los principales grupos de pacientes según la frecuencia de ingresos y el total de días-cama utilizados en el periodo evaluado, lo que da una idea del volumen de recursos generados y la necesidad de estudiar las secuencias de actividades involucradas en su atención.

TABLA 2. CDM CON MAYORES DÍAS-CAMA

\begin{tabular}{|l|c|c|}
\hline \multirow{2}{*}{$\begin{array}{l}\text { Categoría diagnóstica } \\
\text { mayor }\end{array}$} & \multicolumn{2}{|c|}{ Días-cama } \\
\cline { 2 - 3 } & $\mathbf{2 0 0 4}$ & $\mathbf{2 0 0 5}$ \\
\hline $\begin{array}{l}\text { Enfermedades y } \\
\text { trastornos del sistema } \\
\text { circulatorio }\end{array}$ & 230 & 110 \\
\hline $\begin{array}{l}\text { Enfermedades y } \\
\text { trastornos del sistema } \\
\text { nervioso }\end{array}$ & 99 & 142 \\
\hline $\begin{array}{l}\text { Enfermedades y } \\
\text { trastornos del sistema } \\
\text { respiratorio }\end{array}$ & 142 & 160 \\
\hline $\begin{array}{l}\text { Enfermedades y } \\
\text { trastornos del sistema } \\
\text { digestivo }\end{array}$ & 165 & 127 \\
\hline
\end{tabular}

Fuente: (53)
Mediante el estudio de tiempos, con ayuda de la distribución Beta y el modelado de procesos con la técnica IDEF3, se determinó la duración del ciclo del proceso y la duración total. Así, se identificaron las actividades que más inciden en la duración del ciclo operativo, como es el caso de la confección de la historia clínica, la cual depende de su extracción de registros o admisión y de plasmar la información con los resultados del examen físico, la entrevista al paciente y la entrega de resultados de los complementarios. Entre tanto, el 63\% del ciclo total se distribuye entre los tiempos de espera, las interrupciones y los tiempos de aprovisionamiento.

El análisis de los riesgos asociados a los procesos de atención de estos grupos de pacientes reveló la no oportuna detección de problemas reflejados en la historia clínica, la incorrecta orientación del tratamiento, la innecesaria orientación de estudios diagnósticos, la aparición de síntomas no detectados a tiempo en el paciente durante su evolución, la ocurrencia de infecciones (sepsis urinaria, flebitis) y estrés en el personal. El no completamiento, en determinados periodos, de las historias clínicas trae como consecuencia fallos en el seguimiento a los pacientes hospitalizados, posibles complicaciones o decisiones erróneas, lo cual puede llegar a ser grave, de acuerdo a la complejidad de cada caso.

Con las valoraciones precedentes se evaluó el nivel de servicio a los pacientes, basado en el comportamiento de tres parámetros críticos, derivados de las encuestas de calidad a pacientes y los cuestionarios aplicados al personal asistencial, estos son: fiabilidad de los suministros, tiempos de entrega e información (tabla 3). Entonces, el nivel de servicio alcanzó un valor de $48 \%$, motivado por un comportamiento entre regular y bajo del aseguramiento de los recursos y de los tiempos de entrega, como se percibió previamente. 
Tabla 3. NiVel de SERVicio a PaCientes y aCOMPañantes

\begin{tabular}{|l|c|c|c|c|c|c|c|}
\hline Parámetros & $\begin{array}{c}\text { Peso } \\
\text { relativo }\end{array}$ & $\mathbf{5}$ & $\mathbf{4}$ & $\mathbf{3}$ & $\mathbf{2}$ & $\mathbf{1}$ & Total \\
\hline Fiabilidad de los suministros & 0.3 & & & $\mathbf{x}$ & & & 0.9 \\
\hline Información & 0.4 & & & $\mathbf{x}$ & & & 1.2 \\
\hline Tiempo de entrega del servicio & 0.3 & & & & & $\mathbf{x}$ & 0.3 \\
\hline Total & \multicolumn{7}{|c|}{} \\
\hline Nivel de servicio
\end{tabular}

Fuente: (53)

De manera general, las herramientas aplicadas facilitaron la identificación de insuficiencias en: la organización y el diseño de los procesos y su capacidad operativa; el aporte de valor de las actividades; la gestión de los suministros basada en su impacto en la asistencia médica; la utilización de los recursos (cama hospitalaria, salones quirúrgicos) y de los tiempos; e igualmente destacó la pertinencia de asociar estos análisis a las características clínicas de los pacientes, un aspecto que puede complejizar la gestión de procesos asistenciales.

Cierra esta fase la propuesta de un programa de mejoras, relativas a: la sistematización de métodos clínicos y protocolos terapéuticos; la transferencia de buenas prácticas internas y externas; el diseño de sistemas de programación de salones quirúrgicos y distribución de materiales médicos y no médicos, con base en la coordinación entre los procesos de apoyo y los servicios asistenciales; la reducción de los tiempos de entrega mediante la eliminación de actividades que no aportan valor y la automatización de otras de gran aporte; la gestión preventiva basada en riesgos y el diseño de puntos críticos de control, junto a potenciar la medición del desempeño hospitalario, haciendo uso de un sistema de indicadores clave.

78 Fase IV. Seguimiento y control. Diseño del índice integral de desempeño de los procesos hospitalarios. Como parte del sistema de seguimiento y control se diseña un índice integral que engloba un número significativo de indicadores que miden eficacia, eficiencia y calidad de los procesos hospitalarios. Los pasos para su diseño son:

1. Selección de indicadores. Se consultaron fuentes bibliográficas que exploran aspectos relacionados con los indicadores hospitalarios, aparejado al análisis de aquellos referidos como fundamentales en las organizaciones estudiadas.

Este listado se redujo por medio del método Delphi (tabla 4), aplicado a expertos seleccionados en estas instalaciones, para obtener seis indicadores que dichos expertos coincidieron en que son útiles y ampliamente utilizados en la gestión hospitalaria: estadía hospitalaria, índice ocupacional, tasa de infecciones intrahospitalarias, índice de positividad de los medios diagnósticos, índice de operaciones suspendidas y mortalidad neta. Para el caso específico del proceso quirúrgico del hospital general resultaron los indicadores: rendimiento quirúrgico por salón; estadía preoperatoria; índice de reintervenciones; índice de operaciones suspendidas, y operaciones por especialista quirúrgico.

2. Estimación de su peso relativo. Para estimar el peso relativo de los indica- 
TABLA 4. IDENTIFICACIÓN DE EXPERTOS POR HOSPITAL

\begin{tabular}{|l|l|l|l|l|}
\hline \multicolumn{2}{|l|}{ Expertos /hospital/coeficiente de experticia } & \\
\hline $\begin{array}{l}\text { Clínico-quirúr- } \\
\text { gico 1 }\end{array}$ & Provincial & Ginecobstétrico & $\begin{array}{l}\text { Clínico-quirúr- } \\
\text { gico 2 }\end{array}$ & Hospital general \\
\hline Experto $1 / 0.91$ & Experto $1 / 0.89$ & Experto /0.93 & Experto $1 / 0.87$ & Experto $1 / 0.95$ \\
\hline Experto 2/0.93 & Experto $2 / 0.84$ & & Experto 2/0.89 & Experto 2/0.72 \\
\hline Experto 3/0.91 & Experto 3/0.93 & & Experto 3/0.93 & Experto 3/1 \\
\hline Experto 4/0.86 & Experto 4/0.91 & & Experto 4/1 & Experto 4/1 \\
\hline Experto 5/0.81 & Experto 5/0.88 & & Experto 5/0.80 & Experto 5/0.75 \\
\hline Experto 6/0.80 & Experto 6/0.98 & & Experto 6/1 & Experto 6/1 \\
\hline Experto 7/0.89 & Experto 7/0.87 & & Experto 7/0.92 & Experto 7/0.87 \\
\hline & & & Experto 8/1 & \\
\hline & & & Experto 9/0.92 & \\
\hline
\end{tabular}

Fuente: (53) y (55)

dores se utilizó el método $\mathrm{AHP}^{2}$ y se obtuvo que la estadía hospitalaria, el índice ocupacional y la tasa de infección intrahospitalaria poseen los pesos mayores. Esto se debe a que son los más utilizados en la gestión del día a día en las organizaciones hospitalarias.

3. Confección del índice integral. Para el cálculo del índice integral se desarrolló la expresión (1), que muestra una comparación entre el máximo nivel que puede ser alcanzado (en el caso de que todos los indicadores obtengan la más alta puntuación), y el que posee cada indicador de acuerdo a su comportamiento real.

$$
\text { IDhosp }=\frac{\sum_{j=1}^{Q} P j * V j}{5 \sum_{i}^{Q} V_{j}}
$$

2 Un número creciente de investigaciones utiliza este método para otorgar un peso relativo a los indicadores de los índices integrales propuestos.
Donde:

IDhosp: índice integral de desempeño de los procesos hospitalarios.

$P j$ : puntuación del indicador j-ésimo.

$V j$ : peso relativo del indicador j-ésimo.

$Q$ : cantidad de indicadores que se integran al índice.

4. Determinación de la forma de evaluación. La escala utilizada es de 1 a 5 , tomando la tendencia de los indicadores precedentes estudiados. Para el caso de indicadores como la mortalidad, para valores muy elevados la puntuación otorgada es cero.

Para normalizar la evaluación de los indicadores se describe el valor deseado (propósito), los rangos para cada propósito y la puntuación que se otorga de acuerdo a dicho rango en la escala utilizada. De esta forma se describe el comportamiento de los indicadores para cuatro hospitales (tabla 5). 


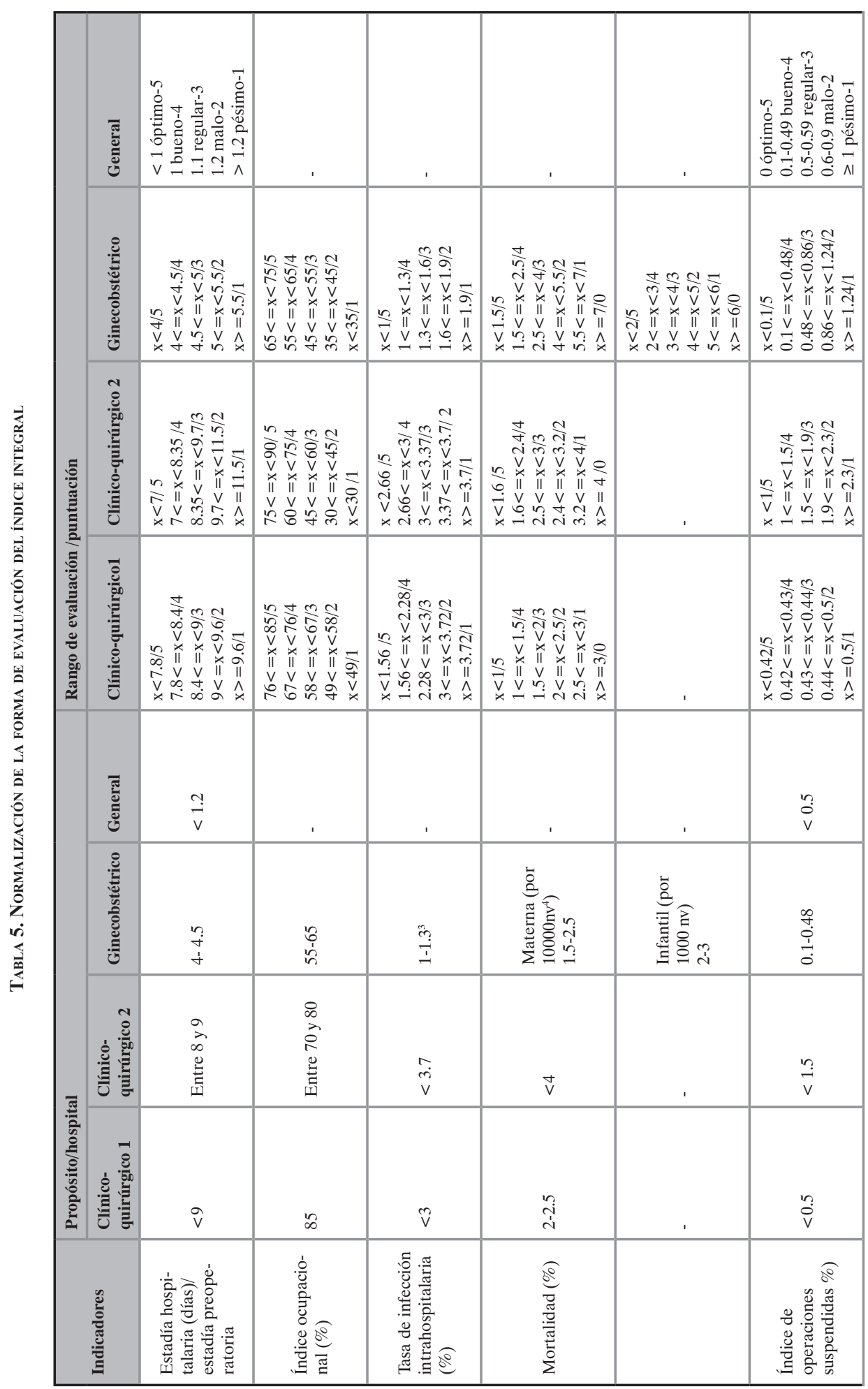




\begin{tabular}{|c|c|c|c|c|c|}
\hline & 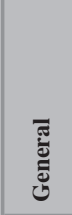 & ' & 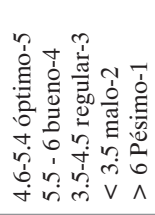 & 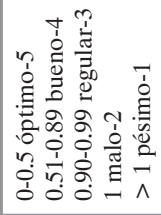 & 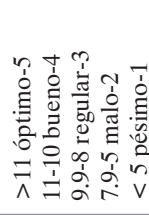 \\
\hline & 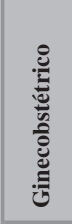 & 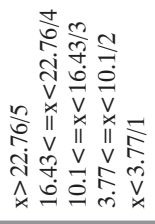 & & & \\
\hline 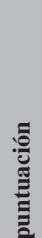 & 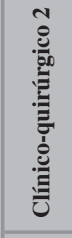 & 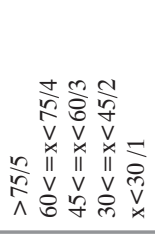 & & & \\
\hline 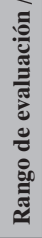 & 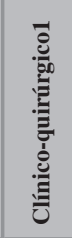 & 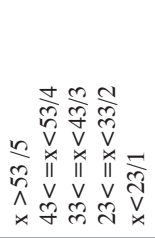 & & & \\
\hline \multirow{4}{*}{ 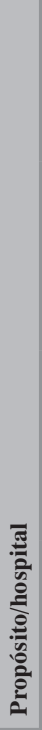 } & 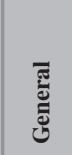 & & $\begin{array}{l}0 \\
\mathrm{VI} \\
\because \\
+ \\
\wedge\end{array}$ & 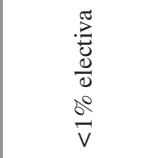 & \multirow[t]{2}{*}{$\exists$} \\
\hline & 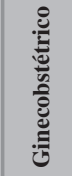 & 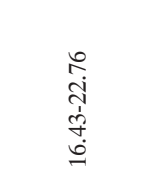 & & & \\
\hline & 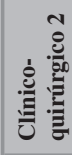 & $\begin{array}{l}\stackrel{0}{1} \\
\end{array}$ & & & \\
\hline & 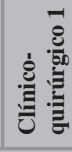 & 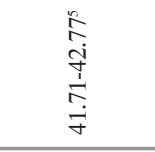 & & & \\
\hline & 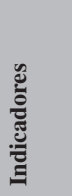 & 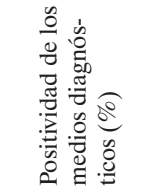 & 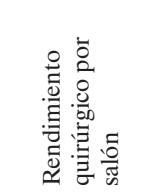 & 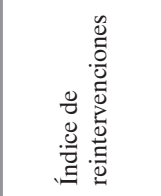 & 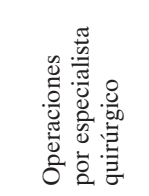 \\
\hline
\end{tabular}

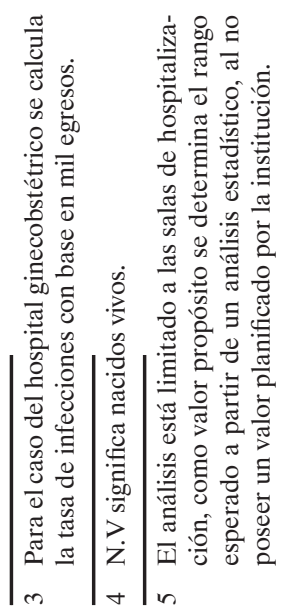


5. Escala de evaluación del índice integral. Para una primera aproximación, los análisis del comportamiento del índice se harán de acuerdo a una escala donde se considerará excelente para 0.80-1.00, buena para $0.60-0.80$, regular para 0.40 0.60, mala $0.20-0.40$ y pésima $0.00-0.20$.

La concepción de este índice se produjo de forma paralela a las etapas iniciales de introducción de la gestión por procesos, para luego constituirse en una herramienta con carácter dual en el procedimiento metodológico empleado, pues, a la vez que se utiliza en la retroalimentación y control en esta fase, su medición puede ser el punto de partida en el diagnóstico de la organización (fase I).

Su evaluación en los principales hospitales estudiados revela y comprueba dificultades que pueden generalizarse como referentes a la calidad de la atención y la eficiencia operativa de los procesos asistenciales y clínicos estudiados, de acuerdo al estudio de la dinámica de indicadores como la estadía hospitalaria, la mortalidad, el índice de reintervenciones, el índice de operaciones suspendidas y el rendimiento quirúrgico por salón (tabla 6).

Tabla 6. Situación INICIAL del DESEMPEÑo de LOS PROCESOS EN CUATRO HOSPITALES MATANCEROS

\begin{tabular}{|c|c|c|c|c|c|}
\hline \multirow[b]{2}{*}{ Indicadores/hospital } & \multirow[b]{2}{*}{$\begin{array}{c}\text { Peso } \\
\text { relativo } \\
(\mathbf{V j})\end{array}$} & \multicolumn{3}{|c|}{ Puntuación } & \multirow[b]{2}{*}{ General } \\
\hline & & $\begin{array}{c}\text { Clínico- } \\
\text { quirúrgico } 1\end{array}$ & Ginecobstétrico & $\begin{array}{c}\text { Clínico } \\
\text { quirúrgico } 2\end{array}$ & \\
\hline Estadía hospitalaria (días) & 0.41 & 2 & 3 & 2 & - \\
\hline $\begin{array}{l}\text { Estadía preoperatoria } \\
\text { (días) }\end{array}$ & 0.08 & - & - & - & 3 \\
\hline Índice ocupacional $(\%)$ & 0.23 & 3 & 3 & 3 & - \\
\hline $\begin{array}{l}\text { Tasa de infección } \\
\text { intrahospitalaria }(\%)\end{array}$ & 0.14 & 5 & 3 & 5 & - \\
\hline Mortalidad (\%) & 0.1 & 3 & 2 & 0 & - \\
\hline $\begin{array}{l}\text { Índice de operaciones } \\
\text { suspendidas }(\%)\end{array}$ & 0.05 & 5 & 4 & 4 & \\
\hline $\begin{array}{l}\text { Índice de operaciones } \\
\text { suspendidas proceso } \\
\text { quirúrgico }(\%)\end{array}$ & 0.28 & - & - & - & 1 \\
\hline $\begin{array}{l}\text { Positividad de los medios } \\
\text { diagnósticos }(\%)\end{array}$ & 0.07 & 3 & 3 & 5 & - \\
\hline $\begin{array}{l}\text { Rendimiento quirúrgico } \\
\text { por salón }\end{array}$ & 0.2 & - & - & - & 2 \\
\hline Índice de reintervenciones & 0.2 & - & - & - & 1 \\
\hline $\begin{array}{l}\text { Operaciones por } \\
\text { especialista quirúrgico }\end{array}$ & 0.42 & - & - & - & 4 \\
\hline IDhosp & & $59.4 \%$ & $60 \%$ & $55.2 \%$ & $48.99 \%$ \\
\hline
\end{tabular}

Fuente: (53) y (55) 


\section{Evaluación de los resultados alcanzados}

Para la evaluación del nivel alcanzado, una vez puesto en práctica un núcleo importante de mejoras, se realizaron mediciones a nivel de organización y procesos y se contrastaron con la situación delineada en el diagnóstico inicial, para así comprobar la eficacia de las propues- tas de mejora y su impacto en el desempeño de los procesos y en la gestión hospitalaria.

Como es visible en la tabla 7 , los niveles de satisfacción de los pacientes y acompañantes muestran un incremento, a la vez que aumenta el rigor en la aplicación de los instrumentos de evaluación, y la mejora en el nivel de

Tabla 7. Evaluación de los Resultados alCaNZados EN EL NIVEL de SERVICIO Y EL DESEMPEÑo de LOS PROCESOS

\begin{tabular}{|c|c|c|c|c|}
\hline \multirow[b]{2}{*}{ Hospitales } & \multirow[b]{2}{*}{ Aspecto } & \multicolumn{2}{|c|}{ Mejora } & \multirow[b]{2}{*}{$\begin{array}{c}\text { Incremento o } \\
\text { disminución } \\
(\%)\end{array}$} \\
\hline & & Antes & Después & \\
\hline \multirow{12}{*}{$\begin{array}{l}\text { Clínico- } \\
\text { quirúrgicos }\end{array}$} & \multicolumn{3}{|l|}{ Servicio ofrecido al paciente y acompañantes } & \\
\hline & \multirow{4}{*}{$\begin{array}{l}\text { Nivel de servicio general }(\%) \\
\text { Eficiencia en el tiempo de entrega (porcentaje del } \\
\text { tiempo total de estancia) } \\
\text { Fiabilidad de los suministros (porcentaje en } \\
\text { tiempo, calidad y cantidad) } \\
\text { Grado de satisfacción de pacientes y } \\
\text { acompañantes }(\%)\end{array}$} & 38 & 60 & 22 \\
\hline & & 37.14 & 41 & 3.86 \\
\hline & & 50 & 83 & 33 \\
\hline & & 97.4 & 99.2 & 1.8 \\
\hline & \multicolumn{3}{|l|}{ Comportamiento de los procesos } & \\
\hline & $\begin{array}{l}\text { Índice de desempeño de los procesos (IDhosp) } \\
(\%)\end{array}$ & 66.8 & 79.8 & 23 \\
\hline & \multirow{4}{*}{$\begin{array}{l}\text { Estadía (días) } \\
\text { Índice ocupacional }(\%) \\
\text { Tasa de infecciones intrahospitalarias }(\%) \\
\text { Índice de positividad de los medios diagnósticos } \\
(\%)\end{array}$} & 9 & 8.2 & 8.9 \\
\hline & & 65.50 & 72.8 & 7.3 \\
\hline & & 1.5 & 1.4 & 0.1 \\
\hline & & 41.2 & 45.8 & 4.6 \\
\hline & $\begin{array}{l}\text { Dinámica de arribo de pacientes (pacientes por } \\
\text { año) }\end{array}$ & 59896 & 60631 & 1.22 \\
\hline \multirow{11}{*}{$\begin{array}{l}\text { Hogar de } \\
\text { ancianos }\end{array}$} & \multicolumn{3}{|l|}{ Servicio ofrecido al adulto mayor y a sus familiares } & \\
\hline & Nivel de servicio general $(\%)$ & 38 & 86 & 48 \\
\hline & Eficiencia en el tiempo de entrega $(\%)$ & 65.21 & 92.78 & 27.57 \\
\hline & $\begin{array}{l}\text { Nivel de actividad (cantidad de pacientes } \\
\text { atendidos días/paciente) }\end{array}$ & 39055 & 44165 & 13.1 \\
\hline & Calidad en la información (\%) & 75 & 90 & 15 \\
\hline & Fiabilidad en entrega de insumos (\%) & 70 & 91 & 21 \\
\hline & \multicolumn{3}{|l|}{ Calidad de vida } & \\
\hline & Mortalidad (\%) & 28.4 & 24 & 4.4 \\
\hline & $\begin{array}{l}\text { Porcentaje de pacientes con estancia de más de } \\
\text { un año }\end{array}$ & 14.28 & 57.8 & 43.68 \\
\hline & Casos de ancianos con escabiosis & 139 & 104 & 25.2 \\
\hline & Casos de ancianos con micosis & 42 & 21 & 50 \\
\hline
\end{tabular}

Fuente: elaboración propia 


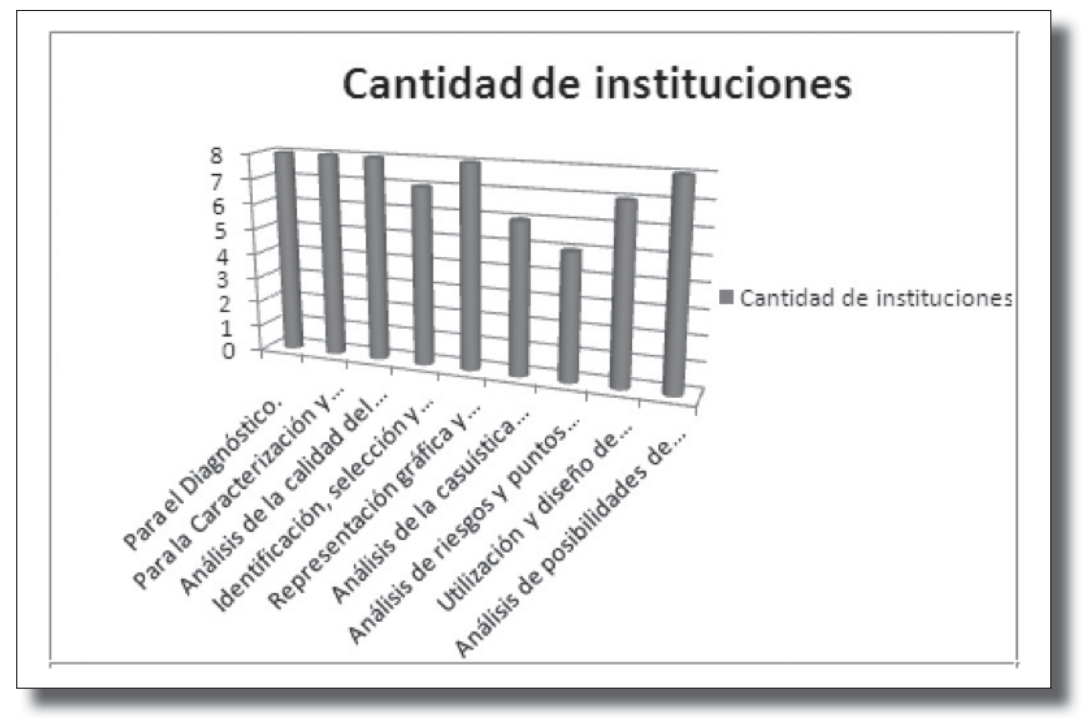

Figura 6. Generalización de los Resultados en CENTros de SAlud Matanceros

Fuente: elaboración propia

servicio del proceso se constata a través del comportamiento de sus parámetros.

La extensión del procedimiento y las herramientas propuestas a otras organizaciones demuestra su factibilidad y posibilidad de generalización; entonces, este ha sido aplicado total o parcialmente en ocho instituciones hospitalarias (figura 6).

\section{Discusión}

El procedimiento para incorporar la gestión por procesos en instalaciones hospitalarias tiene como principal característica la integración de diversas herramientas y métodos de utilidad en la caracterización, el diagnóstico, la mejora y el control, además de su flexibilidad de utilización. Precisamente, la clasificación de las instituciones de salud reveló que, de manera análoga a los procesos industriales, existe intermitencia en las actividades, pues su ejecución responde a las complejidades clínicas de los pacientes; lo que conlleva conferirle gran importancia a estudiar los tipos de pacientes que arriban o se alojan en el hospital, por cuanto esto define secuencias de tratamiento y consumo de recursos, entre otros aspectos de la gestión.

El uso de un índice integral posibilitó: la evaluación de la gestión de los procesos hospitalarios para un número reducido y relevante de indicadores; la comparación entre diferentes procesos internos similares y hospitales de igual perfil; la búsqueda de oportunidades de mejora, vía el análisis de los inductores de actuación y su relación con los procesos donde se origina la desviación; y el análisis de la efectividad de las soluciones implementadas y proyectadas.

En cuanto a las brechas detectadas a partir de la descripción de los procesos, la evaluación de entradas y proveedores, el análisis de valor añadido y de la casuística hospitalaria responden a dedicar esfuerzos en la organización y al diseño de los procesos y su capacidad operativa, la mejora en el aporte de valor, la gestión de los suministros basada en su impacto en la asistencia médica y la reducción de los tiempos. Por último, se lograron avances en la gestión, refle- 
jados en el comportamiento del índice integral de desempeño de los procesos hospitalarios (IDhosp) y el nivel de servicio, antes y después de aplicados los instrumentos propuestos para los hospitales clínico-quirúrgicos, en tanto para el hogar de ancianos se constata dicho progreso a través del nivel de servicio y otros indicadores más específicos y propios de su actividad; lo anterior motivó la generalización de los resultados a otras instituciones para demostrar así la viabilidad de los instrumentos en la mejora del desempeño hospitalario.

\section{Conclusiones}

El estudio de varios procedimientos para la gestión por procesos, elaborados por autores nacionales e internacionales, revela la existencia de un grupo de herramientas útiles para potenciar el perfeccionamiento de los procesos, las cuales constituyen actualmente buenas prácticas en la gestión empresarial.

En Cuba los servicios de salud demandan la introducción de estas herramientas en sus sistemas de gestión, tal y como lo plantea el Sistema de Salud en sus proyecciones de trabajar por la excelencia en los servicios.

La aplicación de un grupo de estas herramientas en instituciones hospitalarias matanceras, asociadas a un procedimiento para la inserción de la gestión por procesos refleja, en los resultados obtenidos, su utilidad y pertinencia para la mejora de los procesos hospitalarios y su contribución, por ende, a la calidad del servicio que ellas brindan.

\section{Referencias}

1. Organización Mundial de la Salud (OMS). Estadísticas sanitarias mundiales. Washington: OMC; 2009.

2. Bonafont X, Casasín T. Protocolos terapéuticos y vías clínicas. Farmacia Hospitalaria. 2004; 28(6):82-100.
3. Claveranne JP, Pascal C. Repenser les processus a l'hopital. Une methode au service de la performance París: Medica Editions; 2004.

4. Equiza Escudero JJ. Gestión hospitalaria: nuevas tendencias. Revista Valenciana de Estudios Autonómicos. 1999; (28):31-40.

5. Roth AV, van Dierdonck R. Hospital resource planning: Concepts, feasibility, and framework. Production and Operations Management. 1995; 4:2-29.

6. Butler TW, Leong GK, Everett LN. The operations management role in hospital strategic planning. Journal of Operations Management. 1996; 14:137-56.

7. Langabeer Ii JR. Health care operations management: A quantitative approach to business and logistics. University of Texas School of Public Health; 2008.

8. Rechel B, Wright S, Barlow J, Mckee M. Planificación de la capacidad hospitalaria: desde la medición de existencias hasta el modelado de flujos. Boletín de la Organización Mundial de la Salud. 2012.

9. Acosta Chávez M. El hospital en el siglo XXI. Revista Horizonte Médico. 2008; 8(2):56-9.

10. Hsieh NC, Lee KC, Chen W. The transformation of surgery patient care with a clinical research information system. Expert Systems with Applications. 2013; (40):211-21.

11. Ruiz Iglesias L. ¿A qué nos referimos cuando hablamos de gestión clínica? Investigación Clínica y Farmacéutica. 2004; 1(4):24-34.

12. Hsieh NC, Lee KC, Chen W. The transformation of surgery patient care with a clinical research information system. Expert Systems with Applications. 2013; 40:211-21.

13. Vergeles Blanca JM. La gestión de riesgos sanitarios y seguridad del paciente en atención primaria de salud. $9^{\circ}$ Congreso Nacional de la Asociación Española de Gestión de Riesgos Sanitarios. Salamanca, España, 2006.

14. Vitaller Burillo J. El contexto de la gestión de riesgos de la asistencia sanitaria Revista de Calidad Asistencial. 2005; 20(2): 51-52.

15. Carrada Bravo T. Benhmarking y los grupos relacionados con el diagnóstico hospitalario. Rev Med IMSS. 2002; 40(1):25-33.

16. Gómez Jiménez J, Faura J, Burgues L, Pamies S. Gestión clínica de un servicio de urgencias hospitalario: indicadores de calidad, benchmarking y análisis de la casuística (Case-Mix). Gestión Hospitalaria. 2004; 15(1): 3-12.

17. Evers L, van Oostrum JM, Wagelmans APM. Levelled bed occupancy and controlled waiting lists using master surgical schedules [Internet]. 2010. Disponible en: http://hdl.handle.net/1765/21241

18. Quiros Moratos T, Cuesta Peredo D. Sistemas de información en las instituciones sanitarias. Una visión operativa. 2005.Curso experto en Economía de la Salud, Palma de Mayorca, España [Internet]. Disponible en: http://www.informedica.org.ar/pdf/ sadio/2/cheguhem-esp.PDF

19. Carnero Gómez R, Rodríguez Barrios JM. Impacto de los grupos relacionados por el diagnóstico en los 
"Medical devices". Economía de la Salud. 2008; 5(4):216-22.

20. Gemmel P, Vandaele D, Tambeur W. Hospital process orientation (HPO): The development of a measurement tool. Total Quality Management. 2008; 19 (12):1207-17.

21. Spanyi A. More for less: The power of process management. Tampa, Florida: Meghan-Kiffer Press; 2008.

22. Harmon $\mathrm{P}$, Wolf $\mathrm{C}$. The state of business process management. BPTrends; 2010.Duke University, Estados Unidos.

23. Smith H, Fingar P. Business process management - the third wave. Tampa, Florida: Meghan-Kiffer Press; 2003.

24. Deming WE. Quality, productivity, and competitive position. Cambridge, MA: MIT Center for Advanced Engineering Study; 1982.

25. Hammer M, Champy J. Reengineering the corporation: A manifesto for business revolution. NuevaYork: Harper Business; 1993.

26. Melão N, Pidd M. A conceptual framework for understanding business processes and business process modelling. Information Systems Journal. 2000; 10 (2):105-29.

27. Krafzig D, Banke K, Slama D. Enterprise SOA: service-oriented architecture best practices. NJ, Estados Unidos: Prentice Hall-PTR; 2005.

28. Hung RY. Business process management as competitive advantage: A review and empirical study. Total Quality Management. 2006; 17(1):21-40.

29. Rosemann M, Vom Brocke J. The six core elements of business process management. En: Handbook on business process management I. Nueva York: Springer; 2015. p. 105-22.

30. Ravesteyn P. A study into the critical success factors when implementing business process management systems. Managing worldwide operations and communications with information technology [Internet]; 2007. p. 1291-3. Disponible en: https://www.researchgate.net/profile/ Pascal_Ravesteyn/publication/46702063A_Study_ into_the_Critical_Success_Factors_when_Implementing_Business_Process_Management_Systems/ links/545a10540cf2 bccc4912ff58.pdf

31. Leu JD, Huang YT. An application of business process method to the clinical efficiency of hospital. Journal of Medical Systems. 2009; 35(34):9-21.

32. Becker J, Fischer R, Janiesch C. Optimizing us health care processes-a case study in business process management. En: AMCIS 2007 Proceedings; 2007.

33. Stephenson C, Bandara W. Enhancing best practices in public health: Using process patterns for business process managemented. En: Proceedings of the 15th European Conference on Information Systems University of St. Gallen; 2007. p. 2123-34.

34. Kolker A. Process modelling of emergency department patient flow: Effect of patient length of stay on ed diversion. J Med Syst. 2008; (32): 389-401.
35. Bertolini M. Business process re-engineering in healthcare management: A case study. Business Process Management Journal. 2011; 17(1):42-66.

36. Scheuerlein H, Rauchfuss F, Dittmar Y, Molle R, Lehmann T, Pienkos N, Settmacher U. New methods for clinical pathways - business process modeling notation (bpmn) and tangible business process modeling (t. Bpm). Langenbeck's Archives of Surgery. 2012; 397(5):755-1.

37. Fernández Sánchez E. Dirección de la producción i. Fundamentos estratégicos. Madrid: Civitas; 1993.

38. Hernández Nariño A, Medina León A, Nogueira Rivera D, Negrín Sosa E, Marqués León M. La caracterización y clasificación de sistemas, un paso necesario en la gestión y mejora de procesos. Particularidades en organizaciones hospitalarias. Dyna. 2014; 81(184):193-200.

39. Schroeder RG. Administración de operaciones. Toma de decisiones en la función de operaciones. México D. F.: McGraw-Hill; 1992.

40. Nogueira Rivera D, Medina León A, Nogueira Rivera C. Fundamentos del control de gestión empresarial. Ciudad de La Habana: Editorial Pueblo y Educación; 2004.

41. Amozarrain M. La gestión por procesos. s.1.: Mondragón; 1999.

42. Saaty T. The analytic hierarchy process. Nueva York: McGraw-Hill; 1981.

43. Trischler WE. Mejora del valor añadido en los procesos. Barcelona: Ediciones Gestión 2000; 1998.

44. Biazzo S, Bernardi G. Process management practices and quality systems standards. Risk and opportunities of the new ISO 9001 certification. Business Process Management Journal. 2003; 9(2):149-69.

45. Hernández Nariño A, Medina León A, Nogueira Rivera D. Influencia de la actividad logística en la gestión de los procesos hospitalarios. Revista Logística Aplicada. 2009; (13).

46. Medina León A, Nogueira Rivera D, Hernández Nariño A, Viteri Moya JR. Relevancia de la gestión por procesos en la planificación estratégica y la mejora continua. Ecuador. Revista Eídos. 2010; 1(2):101-30. Disponible en: http://www.ute.edu.ec/ posgrados/EIDOS2.pdf

47. Hodson WK. Maynard: Manual del ingeniero industrial I, cuarta edición. México: McGrawHill; 2004.

48. Sánchez Lara A. Planificación y control de la producción. Ciudad Habana: Universidad de la Habana, Escuela de Ingeniería Industrial; 1979.

49. Fonseca Hernández M, Rodríguez Buergo D, Peraza Ramos JM, Bonet Collazo O, Vila Díaz J, Jorge Cruz N. Comportamiento de indicadores hospitalarios durante el decenio 1990-1999. Hospital pediátrico universitario "Paquito González Cueto". Revista Cubana de Pediatría. 2001; 73(3):158-64.

50. Segura Sardinas O, Lozano Álvarez E, Guillén Godales T, Herrera Domínguez H. Construcción de un indicador sintético para medir diferencias en los servicios hospitalarios. Correo Científico Médico [Internet]. 2004; 8(1). Disponible en: http://www. cocmed.sld.cu/no81/n81ori2.htm 
51. Frías Jiménez R, González Arias M, Cuétara Sánchez L, Corzo Sánchez Y, González Laucirica A. Herramientas de apoyo a la solución de problemas no estructurados en empresas turísticas (Haspnet). Matanzas, Cuba: Universidad de Matanzas; 2008.

52. Hernández Nariño A. Contribución a la gestión y mejora de procesos en instalaciones hospitalarias del territorio matancero [tesis en opción al grado científico de doctor en Ciencias Técnicas]. Universidad de Matanzas "Camilo Cienfuegos", Facultad Industrial-Economía; 2010-

53. Hernández Nariño A, Nogueira Rivera D, Medina León A, Marqués León M. Inserción de la gestión por procesos en instituciones hospitalarias. Concepción metodológica y práctica. Revista de Administração da Universidade de São Paulo. 2013; 48(4):739-56.
54. Delgado Landa A. Herramientas de la investigación de operaciones para abordar problemas de decisión en el proceso quirúrgico del hospital julio M. Aristegui Villamil [Tesis en opción al título de máster en Administración de Empresas. Mención: Administración de Negocios]. Universidad de Matanzas "Camilo Cienfuegos", Facultad de Ciencias Económicas e Informática; 2013.

55. Nogueira Rivera D. Modelo conceptual y herramientas de apoyo para potenciar el Control de Gestión en las empresas cubanas [tesis en opción al grado científico de doctor en Ciencias Técnicas]. Matanzas, Cuba: Universidad de Matanzas "Camilo Cienfuegos", Facultad Ingeniería IndustrialEconomía; 2002. 


\section{Resumen}

El Sistema Nacional de Salud Cubano se plantea como reto el perfeccionamiento de la gestión de sus instituciones, para lo cual considera objetivos medulares: fomentar la creatividad y la innovación, impulsar la formación permanente, buscar la eficiencia, estudiar buenas prácticas internacionales y propiciar una constante evaluación de los procesos. Estos propósitos son comunes a enfoques gerenciales frecuentemente adoptados por las organizaciones que buscan calidad, eficiencia, eficacia y mejor servicio al cliente. Este trabajo busca ilustrar los resultados de experiencias de gestión por procesos como plataforma de trabajo que impulsa la mejora de los servicios de salud. Para ello muestra la inserción de un procedimiento, resultado del estudio bibliográfico de setenta propuestas metodológicas. Se toman cinco hospitales de una provincia cubana para probar la utilidad de los instrumentos y luego se aprecian los avances en el servicio y el desempeño hospitalario, así como la extensión del estudio a otros hospitales del territorio.

Palabras clave: gerencia; procesos; mejoramiento; servicios de salud

\section{Abstract}

Cuban National System faces an important challenge, which is to consolidate the improvement programs of their institutions; consequently, there are considered key objectives like: fostering creativity and innovation; promoting continuous training; and ensuring the efficiency seeking, the application of best practices and permanent processes evaluation. These objectives are commonly assumed when organizations adopted managerial approaches based on quality, efficiency, effectiveness and service to clients. Hence, this paper shows the results of experiences in business process management, being conceived as a work setting of improvement in health institutions. To seek such goal, it is conducted a bibliography study of 70 methodological procedures, resulting in a new approach that is applied to five hospitals in a Cuban province in order to prove its efficacy for performance improvement, which is illustrated by progress being obtained in service and processes functioning with consequent extension to other hospital of the province.

Keywords: management; processes; improvement; health care services

\section{Resumo}

O Sistema Nacional de Saúde cubano confronta o desafio de melhorar a gestão das suas instituições, para o qual são considerados como objetivos centrais a promoção da criatividade e da inovação, a promoção da aprendizagem permanente, a busca da eficiência, o estudo das melhores práticas internacionais e uma avaliação constante dos processos. Estes efeitos são comuns a abordagens de gestão, muitas vezes adoptadas pelas organizações que buscam qualidade, eficiência, eficácia e melhor atendimento ao cliente. Este trabalho procura ilustrar os resultados de experiências de gestão de processos como uma plataforma de trabalho que impulsiona a melhoria dos serviços de saúde, traves da inserção de um procedimento, resultado da revisão de literatura de setenta propostas metodológicas. Cinco hospitais de uma província cubana são tomados para testar a utilidade dos instrumentos, depois sao avaliados os avances no serviço e o desempenho hospitalar, e finalmente é apresentada a extensão do estudo para outros hospitais da região.

Palavras-chave: gestão; processos, melhoria; serviços de saúde 


\section{Introducción}

Una revisión bibliográfica de textos científicos, investigaciones y libros sobre gestión por procesos y BPM, control de gestión y administración en salud, publicados entre 1985 y 2013, en países como España, Estados Unidos, Brasil, Cuba y otras regiones de Latinoamérica, revela antecedentes importantes en el desarrollo de la gestión hospitalaria, como a continuación se revela.

En el mundo el sector de salud constituye uno de los empleadores más importantes, al ocupar entre el 7 y el $13 \%$ de la mano de obra. Entre el 2000 y el 2006, los gastos aumentaron su participación en el Producto Interno Bruto (PIB), al pasar del 8 al $8.7 \%$ (1); estos datos demuestran el interés que debe prestarse a su gestión.

El servicio hospitalario tiene peculiaridades como: el cliente es el paciente y su acompañante; este no siempre paga el producto o servicio que recibe (característica propia de hospitales públicos, como los pertenecientes al sistema de salud cubano), pero sí evalúa la calidad percibida, y percibe mayor calidad del servicio cuanto más tiempo se invierta en su atención; es el médico quien decide la demanda de servicios, tratamientos y atenciones hospitalarias; $y$, como plantean Bonafont y Casasín (2), existe gran variabilidad en la atención de salud y la práctica clínica.

Las particularidades mencionadas distinguen la gestión de instituciones de salud, por lo que es importante considerar aquellos elementos que los diferencian de otros sistemas, en virtud de adaptar apropiadamente las herramientas que se utilizan.

De acuerdo con Claveranne y Pascal (3), la gestión por procesos puede suavizar estas inconveniencias, a partir del reconocimiento y el análisis de todos los procesos, para a partir de su descripción y características mejorarlos o rediseñarlos. Esto significaría orientar los servicios hospitalarios y funciones dentro de un hospital, desde una perspectiva de procesos. La inserción de este enfoque fue el resultado de una evolución en la gestión hospitalaria.

En la evolución de la gestión hospitalaria, los directivos comenzaron a asumir retos como: los pacientes desempeñan el rol de demandantes con capacidad de optar entre alternativas terapéuticas, profesionales y centros asistenciales; la sociedad promueve estrategias de participación de la comunidad en los asuntos del sector, de transparencia en la toma de decisiones y exige garantías de calidad del servicio, sin que se causen largas estadías hospitalarias o prácticas no correctas; se fomenta la motivación del personal de salud por la excelencia en la asistencia, la investigación y la docencia; y el logro de la eficiencia en la utilización de recursos (4).

Estas instituciones desarrollan iniciativas encaminadas a la planificación y la programación de operaciones (5-8), la gestión del componente humano y del conocimiento y las competencias de los profesionales (9). Comienzan a introducir las tecnologías de la información y las comunicaciones (10), a implementar plataformas logísticas para lograr suministros rápidos de material a los almacenes hospitalarios, lo que propicia estrategias de just-in-time, de reducción de suministros, de mejora de la gestión de sus procesos y la introducción de modelos de gestión clínica $(2,11,12)$.

La gestión y mejora de los procesos y la introducción de modelos de gestión clínica, se benefician de experiencias en: gestión de riesgos (13), análisis de puntos críticos de control (14), utilización del benchmarking $(15,16)$, planificación y programación de operaciones (17) y análisis basados en las 
características clínicas de los pacientes, también conocido como Case Mix $(18,19)$.

El desarrollo del enfoque de procesos en la gestión de organizaciones de salud $(3,20)$, como en el mundo empresarial, ha evolucionado hacia la aplicación de una teoría en franco ascenso: el Business Process Management (BPM), que se considera una herramienta competitiva para las organizaciones $(21,22)$, a la que los gerentes apelan, generalmente, cuando buscan el rediseño de procesos para mejorar la eficiencia operativa, incrementar la conformidad de los productos o servicios o propiciar la innovación (23).

Existen dos tendencias principales, relacionadas en su inicio con esta herramienta: la gestión total de la calidad (TQM) y la reingeniería de procesos (BPR) (24,25); y este vínculo se basa en la idea de que tienen como elemento central de análisis a los procesos (26).

Según Krafzig et al. (27) el BPM se aborda desde dos perspectivas: el contexto del negocio, asociado frecuentemente con iniciativas relativas a la calidad (6 sigma, TQM) o a la propia gestión por procesos (ABC, BSC), y según la perspectiva tecnológica se encuentran soluciones para el modelado de procesos o gestión de flujos (27).

Su evolución transita por el desarrollo de conceptos como la alineación de las operaciones con las prioridades estratégicas, consideradas claves para la competitividad, unidas a otro concepto subyacente e igual de importante: la participación del personal de trabajo (28). Previamente, Zairi (28) había definido al BPM como un enfoque dependiente de elementos estratégicos y operativos, del uso de técnicas y herramientas modernas, el compromiso de los empleados $\mathrm{y}$, esencialmente, de una base horizontal que garantizaría una satisfacción más óptima de los requerimientos del cliente.
En consecuencia, existen seis elementos esenciales en el BPM: la alineación estratégica, la gobernanza, los métodos, la tecnología de información, las personas y la cultura (29).

Estos aspectos han conducido a estudios de factores críticos para el éxito de la implementación de un BPM. Ravesteyn (30) proporciona cinco dimensiones, como son: a) comprensión del BPM (involucra el concepto, la alineación estratégica y el compromiso de la gerencia); b) comprensión del proceso (técnicas de modelado de la calidad, calidad de las fuentes de datos); c) gestión de la integridad del proceso (integralidad de los servicios e integración de las aplicaciones disponibles a través de los servicios); d) calidad de la gestión de proyectos (gestión del cambio y participación del personal); y e) definición de métricas de desempeño (disponibilidad de los datos y organización de la optimización continua) (31).

La aplicación del BPM en salud se asocia a la necesidad de elevar la calidad (32) y la eficiencia en estas organizaciones, con base en el hecho de que los administradores de salud se encuentran bajo grandes presiones para reducir costos, a la vez que se mejore la calidad de la atención (33). A continuación, se enuncian algunos ejemplos que validan esta consideración:

- Introducir el BPM en una instalación médica de Estados Unidos generó mejorías significativas en calidad, eficiencia y seguridad de los pacientes, a partir de la reducción de los tiempos de prevención de infecciones y la disminución de los errores humanos, debido a la informatización de los reportes de infecciones (33).

- La inserción de un enfoque de BPM basado en diseño de patrones y estándares genera beneficios en: el análisis 
de formas más eficientes y eficaces de realizar un proceso; la definición de requerimientos y estándares para el proceso; la asignación de benchmarks para el patrón de comportamiento, con la posibilidad de auditar las áreas de negocio con base en dichos benchmarks; y en el aprendizaje del personal (34).

- Kolker (35) aborda la aplicación del BPM a procesos médicos, a los flujos de pacientes y vías clínicas, para evaluar el efecto de la duración de la estancia del paciente en un departamento de emergencia.

- Bertolini (36) realizó un estudio con un área de neurocirugía de sala del hospital de Parma. Allí definió las etapas de un Business Process Reengineering (BPR), acompañadas de la determinación de los objetivos estratégicos, un levantamiento del mapa de procesos, la representación gráfica de los procesos críticos aplicando la metodología AS IS, así como el rediseño de procesos ya existentes y nuevos.

- El diseño de guías clínicas, herramientas para el aseguramiento de la calidad, optimización de procesos, benchmarking y análisis de costos, en un contexto de BPM, se asocia con la reducción de las complicaciones hospitalarias y la mejora de la documentación sin afectar la duración de la estancia y los costos (37).

Por su parte, el sector de salud cubano, durante muchos años, no había sido favorecido por la utilización de herramientas gerenciales. Primero, la situación financiera del país produjo grandes afectaciones en los servicios de salud, al imposibilitar la obtención de importantes recursos y tecnologías; luego este no había sido un campo ampliamente explotado en cuanto a investigaciones se refiere.
A la luz de estas ideas, desarrollar el enfoque de procesos en organizaciones de salud cubanas representa una línea de trabajo de gran potencial, pues brinda respuestas a algunas de las proyecciones de este sector en la búsqueda de la excelencia.-

\section{Materiales y métodos}

La consulta bibliográfica reflejó el desarrollo de procedimientos metodológicos (setenta), que valoran catorce variables presentes en la gestión y en la mejora. Mediante el método de los clúster se identificaron grupos de procedimientos con características distintivas en el análisis implícito o explícito de un $50 \%$ de las variables; en otro caso, la inclusión parcial de solo el $14 \%$ de estas variables, e incluso la no correspondencia de varios procedimientos con las variables establecidas. De ellos resaltan seis propuestas concebidas para el sector de la salud con similares atributos a aquellos provenientes del sector empresarial.

Como resultado se desarrolló un procedimiento metodológico para la gestión por procesos (figura 1), basado en las fases comunes de la gestión por procesos (análisis, mejora y seguimiento y control) y en su perfeccionamiento y ajuste a las características de las instituciones de salud cubanas, cuatro hospitales y un hogar de ancianos. Dicha metodología está compuesta de cuatro fases, configuradas de la siguiente forma:

Para la fase I (caracterización y diagnóstico) se constituye el equipo de trabajo, de tal manera que se garantice la representatividad de las áreas de resultados clave del hospital. Posteriormente, la caracterización y la clasificación constituyen la vía para familiarizarse con la actividad esencial de la organización y tener una idea inicial de hacia dónde debe apuntar la gestión de sus procesos; para ello se utilizan trece variables adaptadas de 


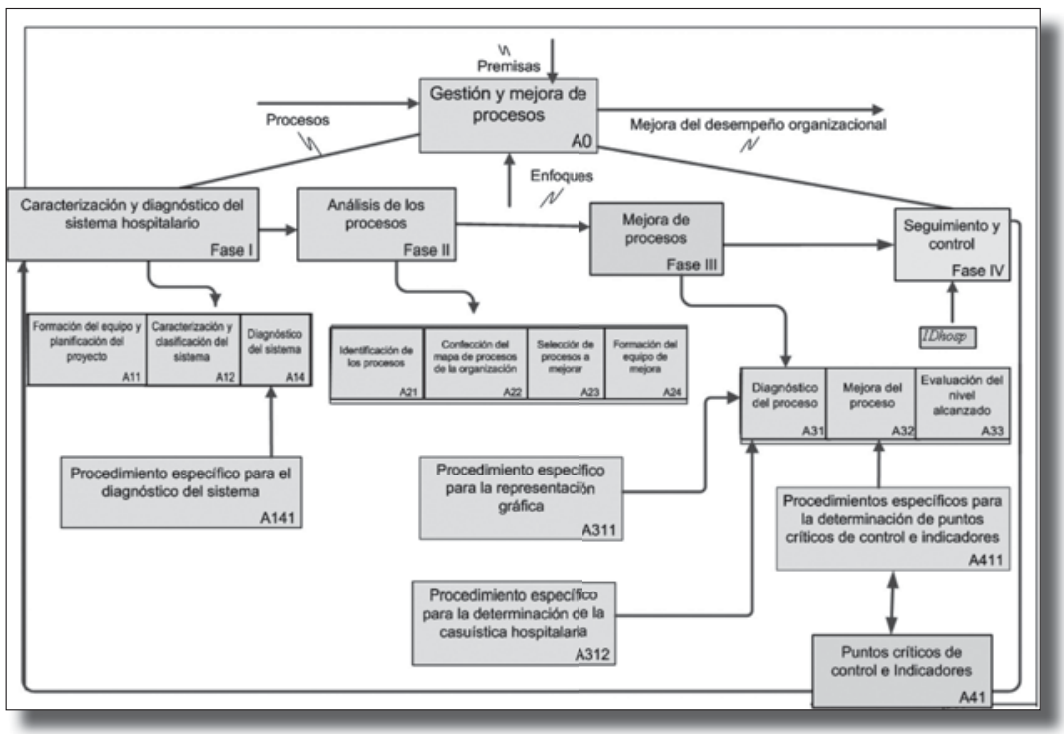

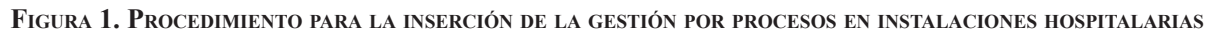
Fuente: (53)

Fernández Sánchez (38) y expuestas en Hernández Nariño et al. (39). Esta fase culmina con el diagnóstico del sistema, sustentado en el triángulo de los servicios propuesto por Schroeder (40).

En la fase II (análisis de los procesos), primero se clasifican los procesos en operativos o clave, estratégicos y de apoyo, para su ilustración en el mapa de procesos. Luego se identifican los procesos relevantes por el método del coeficiente de concordancia de Kendall; de ellos se seleccionan aquellos prioritarios para la mejora, considerando criterios como su alineación a los objetivos estratégicos, su impacto en la satisfacción de los pacientes, su variabilidad o la probabilidad de obtener beneficios a corto plazo, tal como proponen Claveranne y Pascal (3), Nogueira Rivera et al. (41) y Amozarrain (42), y valiéndose de la técnica de proceso analítico de jerarquía (43).

En la fase III (mejora de los procesos) se describe el proceso objeto de estudio, a través de técnicas de representación gráfica como los diagramas As Is (44), los mapas IDEF0 (45) o la ficha de procesos, la cual registra aspectos de interés para la gestión y el control. Después se detectaron las oportunidades de mejora con el uso de herramientas como el análisis de la casuística hospitalaria. Para identificar los principales grupos de pacientes y su influencia en el diseño del servicio (18), sirvió de apoyo el uso de procedimientos de muestreo de historias clínicas durante cuatro años, para así agrupar los pacientes según métodos como GDR (en hospitales clínico-quirúrgicos, ginecobstétricos y generales) y RUG (para hogar de ancianos); evaluación de entradas y proveedores para evaluar cuáles son las entradas del proceso, qué requerimientos deben cumplir y qué evaluación se le confiere a cada proveedor en el cumplimiento de esos requerimientos; (46) análisis de valor añadido, para determinar el aporte de valor de las actividades del proceso a través de su incidencia en los objetivos, su contribución a las expectativas de los grupos de interés, su impacto en las características de calidad y si esta actividad constituye un momento 
de la verdad o no $(47,48)$; y determinación de los tiempos (48), para visualizar reservas de eficiencia en su uso, con la aplicación de la distribución Beta para la determinación de tres tiempos (pesimista, optimista y más probable), considerando la variabilidad de los procesos estudiados, como propone Sánchez Lara (49).

En la fase IV (seguimiento y control) se diseña un índice integral para evaluar el desempeño de los procesos hospitalarios (IDhosp). Para su construcción fue útil una revisión de la literatura sobre indicadores de evaluación de la actividad hospitalaria $(50,51)$. En una revisión documental se identificaron los indicadores principales en la gestión del desempeño de las instituciones hospitalarias tomadas como caso de estudio, se seleccionaron aquellos que caracterizan la gestión del hospital. Con ayuda de expertos previamente elegidos de acuerdo a la metodología de Frías Jiménez et al. (52) y con ayuda del método de proceso analítico de jerarquía (AHP), se definió el peso relativo de los indicadores componentes de un índice integral para la evaluación de la gestión hospitalaria. Finalmente, considerando los tipos de hospitales estudiados, se normalizó la evaluación del comportamiento de cada indicador.

Posteriormente, los resultados obtenidos en un grupo reducido de instituciones de salud se generalizaron hasta abarcar, primero, siete hospitales entre los años 2008 y 2011 —de ellos cuatro de tipo clínico-quirúrgico, una institución ginecobstétrica, una policlínica, un hogar de ancianos $(53,54)$, y luego se replicaron las aplicaciones en un hospital general en el período 2012-2013 (55), todos ubicados en el tercer nivel de acuerdo al número de camas que poseen (entre cero y trescientas camas).

\section{Resultados}

Las experiencias en la aplicación de las herramientas planteadas se centraron en instituciones de salud del territorio matancero, que responden a tres clasificaciones fundamentales: clínico-quirúrgicos, ginecobstétrico y hogar de ancianos. Dicha clasificación incide en el universo de pacientes, los tipos de patologías que atienden estos hospitales y los servicios que ofrecen; lo cual es de interés en los análisis subsiguientes, por cuanto determina el ajuste y la adaptación de las herramientas utilizadas (39).

Las aplicaciones obtenidas se sintetizan a continuación.

\section{Fase I. Diagnóstico de la organización}

El diagnóstico reveló, de manera general, la necesidad de potenciar el enfoque de procesos y aplicar herramientas gerenciales para resolver problemas relativos a la organización de las actividades asistenciales y de apoyo, el aseguramiento de insumos y los sistemas de control de gestión de las organizaciones hospitalarias estudiadas.

\section{Fase II. Análisis de los procesos}

El primer paso en esta fase fue la identificación de los procesos que integran la organización (tabla 1), a partir de agrupar todas las actividades que se realizan, relacionadas con la asistencia (procesos operativos), el aseguramiento de los procesos operativos (procesos de apoyo) y la conducción estratégica (procesos estratégicos).

La representación del mapa de procesos del hospital permitió hacerse una idea clara de los procesos que representan la institución, reconocer aquellos de impacto directo en el paciente y sus acompañantes y que deben 
Tabla 1. Resumen de PRocesos identificados en los hospitales ObJETo de ESTUdio fundamental

\begin{tabular}{|c|c|c|c|}
\hline $\begin{array}{l}\text { Hospitales clínico- } \\
\text { quirúrgicos (1 y 2) }\end{array}$ & $\begin{array}{l}\text { Hospital } \\
\text { ginecobstétrico }\end{array}$ & Hospital general & Hogar de ancianos \\
\hline $\begin{array}{l}\text { Gobierno } \\
\text { hospitalario }\end{array}$ & Gestión económica & Gestión de calidad & $\begin{array}{l}\text { Gestión de la } \\
\text { Dirección }\end{array}$ \\
\hline Gestión económica & Gestión de calidad & Gestión económica & Admisión al hogar \\
\hline Gestión de calidad & $\begin{array}{l}\text { Gestión del capital } \\
\text { humano }\end{array}$ & $\begin{array}{l}\text { Gestión del capital } \\
\text { humano }\end{array}$ & $\begin{array}{l}\text { Servicios técnico } \\
\text { asistenciales }\end{array}$ \\
\hline $\begin{array}{l}\text { Gestión del } \\
\text { conocimiento }\end{array}$ & $\begin{array}{l}\text { Gestión del } \\
\text { conocimiento }\end{array}$ & $\begin{array}{l}\text { Hospitalización } \\
\text { (servicio quirúrgico } \\
\text { lectivo y electivo, } \\
\text { ginecobstetricia) }\end{array}$ & $\begin{array}{l}\text { Servicio de } \\
\text { enfermería }\end{array}$ \\
\hline $\begin{array}{l}\text { Gestión del capital } \\
\text { humano }\end{array}$ & $\begin{array}{l}\text { Hospitalización } \\
\text { (neonatología, } \\
\text { ginecología, parto) }\end{array}$ & $\begin{array}{l}\text { Atención a } \\
\text { urgencias y } \\
\text { emergencias }\end{array}$ & Gestión Económica \\
\hline $\begin{array}{l}\text { Hospitalización } \\
\text { (servicios clínicos, } \\
\text { quirúrgicos) }\end{array}$ & $\begin{array}{l}\text { Atención a } \\
\text { urgencias y } \\
\text { emergencias }\end{array}$ & Medios diagnósticos & $\begin{array}{l}\text { Gestión de recursos } \\
\text { humanos }\end{array}$ \\
\hline $\begin{array}{l}\text { Urgencias y } \\
\text { emergencias }\end{array}$ & Consulta externa & Consulta externa & $\begin{array}{l}\text { Gestión de servicios } \\
\text { generales }\end{array}$ \\
\hline Servicios externos & Medios diagnósticos & Proceso docente & $\begin{array}{l}\text { Servicios de } \\
\text { alojamiento }\end{array}$ \\
\hline Apoyo asistencial & $\begin{array}{l}\text { Gestión de la } \\
\text { información }\end{array}$ & $\begin{array}{l}\text { Gestión de la } \\
\text { información }\end{array}$ & $\begin{array}{l}\text { Gestión de } \\
\text { mantenimiento y } \\
\text { energía }\end{array}$ \\
\hline $\begin{array}{l}\text { Gestión del sistema } \\
\text { informativo }\end{array}$ & Abastecimiento & Gestión logística & $\begin{array}{l}\text { Gestión de } \\
\text { almacenes }\end{array}$ \\
\hline Transporte & Mantenimiento & $\begin{array}{l}\text { Producción y } \\
\text { servicios }\end{array}$ & \\
\hline Intendencia & Servicios generales & & \\
\hline $\begin{array}{l}\text { Abastecimiento } \\
\text { médico }\end{array}$ & Esterilización & & \\
\hline \multicolumn{4}{|l|}{ Servicios generales } \\
\hline \multicolumn{4}{|l|}{$\begin{array}{l}\text { Construcción y } \\
\text { alojamiento }\end{array}$} \\
\hline \multicolumn{4}{|l|}{ Electromedicina } \\
\hline \multicolumn{4}{|l|}{ Ingeniería } \\
\hline $\begin{array}{l}\text { Central de } \\
\text { esterilización }\end{array}$ & & & \\
\hline
\end{tabular}

Fuente: elaboración propia 


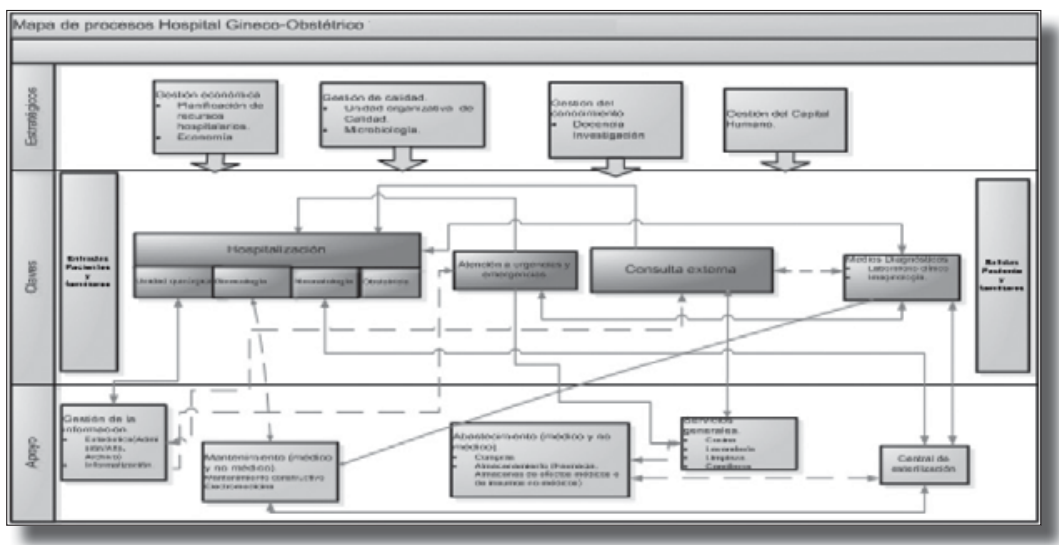

Figura 2. MAPa de procesos hospital ginecobstétrico

Fuente: (53)

tributar al cumplimiento de la misión definida, así como las principales interrelaciones entre cada uno de ellos, lo cual tiene un papel importante en el análisis y mejoramiento de los procesos (figura 2).

En el hospital ginecobstétrico, los procesos que, tal como plantea la ISO, resultan claves para la organización, son: hospitalización (unidad quirúrgica, neonatología, ginecología y obstetricia), atención a urgencias y emergencia, consulta externa y medios diagnósticos. En ejercicio de planificación estratégica ${ }^{1}$ estas resultaron ser las áreas de resultados clave para el cumplimiento de la misión.

La aplicación del principio de que la gestión por procesos se centra en la mejora de aquellos claves para el desempeño de la organización, condujo a la selección de los procesos críticos para la mejora. En este sentido se tuvieron en cuenta dos aspectos:

1 Conducido por un grupo de profesores de los departamentos de Técnicas de Dirección e Ingeniería Industrial de la Facultad Industrial-Economía de la Universidad de Matanzas en el marco de la consultoría realizada en dicho hospital ginecobstétrico. Los autores de este trabajo forman parte de ese grupo consultor.
- Los criterios para la selección de los procesos. Los equipos de trabajo coincidieron en considerar importantes, además de los criterios propuestos por Amozarrain (42) y Nogueira Rivera (56) (impacto en los objetivos estratégicos, impacto en el cliente y éxito a corto plazo), la variabilidad (hospital clínico quirúrgico 1, hospital clínico quirúrgico Il, hospital ginecobstétrico y hogar de ancianos), la repetitividad y el peso económico (hospital ginecobstétrico).

- El análisis del nivel de importancia que el equipo de trabajo le concede a cada criterio. Para asignarle el peso relativo se utilizó el método AHP (proceso analítico de jerarquía) (figura 3).

De estos análisis se seleccionaron, generalmente, como procesos críticos para la mejora: hospitalización y alojamiento, medios diagnósticos, urgencias y emergencias y relativos a servicios de enfermería.

\section{Fase III. Mejora de procesos}

En esta fase se utiliza, de forma gradual, un grupo de herramientas para buscar oportunidades de mejora, como son: diagramas 


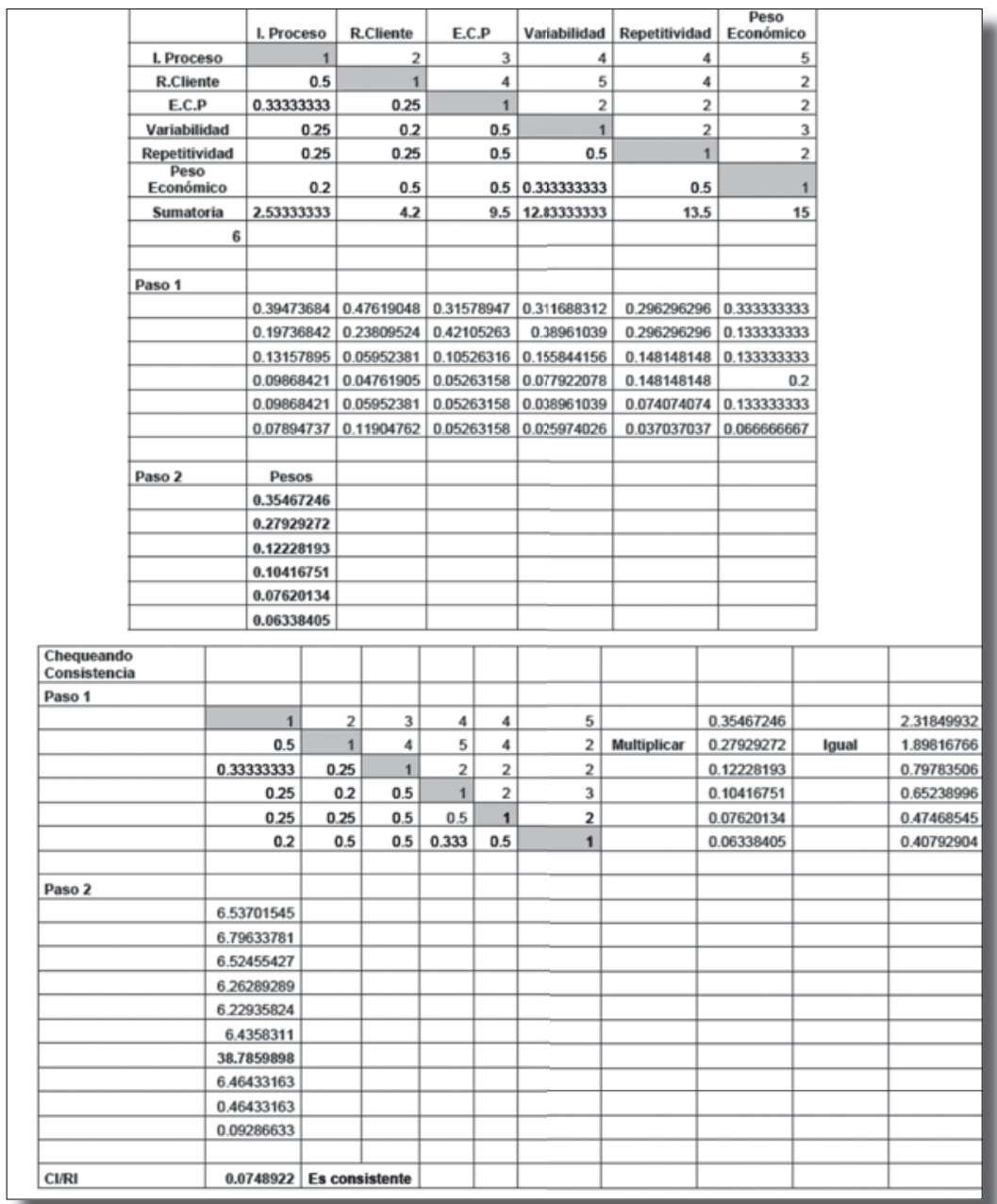

Figura 3. Aplicación del método AHP en el hospital ginecobstétrico

Fuente: (53)

As Is y técnicas IDEF0, fichas de procesos, análisis de valor añadido, estudios de los tiempos de ejecución, evaluación del nivel de servicio, análisis de riesgos e identificación de la casuística hospitalaria.

La descripción del proceso de medicina interna en el hospital clínico-quirúrgico, a partir de un diagrama As Is (figura 4) y su ficha de proceso (figura 5), permitió caracterizarlo y clasificarlo en proceso de alto contacto con el paciente, de relativamente baja intensidad de la mano de obra y alta adaptación, lo que lo define como taller de servicio.

El análisis del valor añadido de las actividades, utilizando como criterios: los objetivos del proceso, los momentos de verdad, las características de calidad y las expectativas de los grupos de interés del proceso, se enfocó en valorar en qué medida cada actividad, identificada en el diagrama As Is, cumple con los criterios enunciados. 
Arialys Hernández-Nariño • Adriana Delgado-Landa $・$ Maylín Marqués-León • Dianelys Nogueira-Rivera • Alberto Medina-León • Ernesto Negrín-Sosa

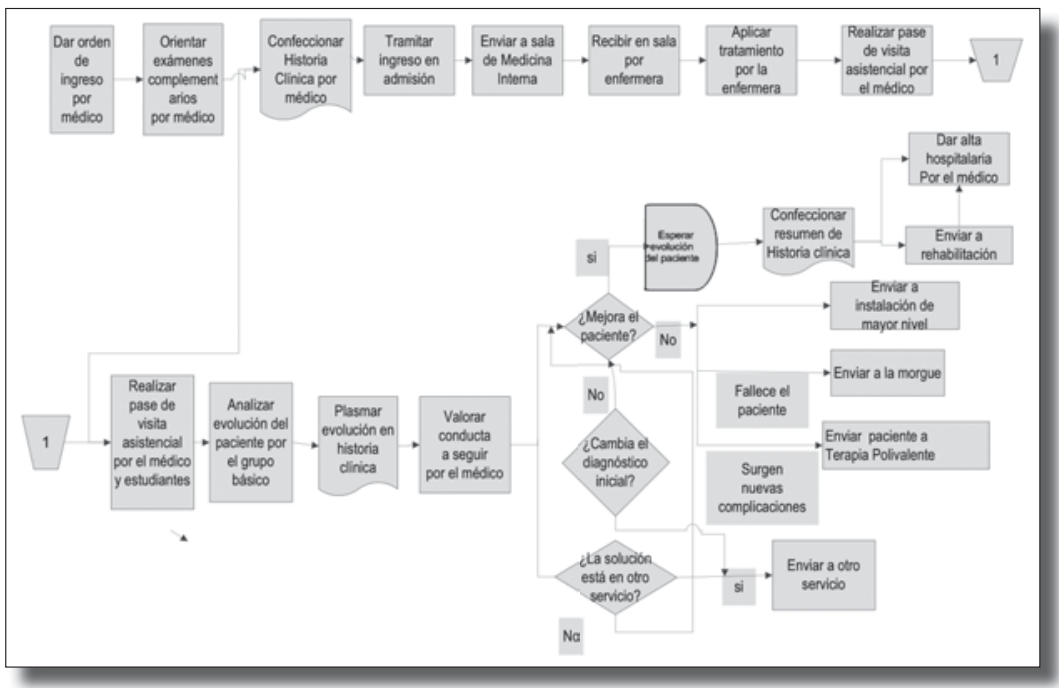

Figura 4. Diagrama As Is de un proceso de medicina interna

Fuente: (53)

Responsable: Jefe del Servicio Medicina Interna $\quad$ Tipo de Proceso: Operativo Finalidad del Proceso: Estudiar y prevenir las enfermedades clínicas y quirúrgicas, ungentes y no urgentes de todo el organismo. Es el encargado de la definición diagnóstica y terapéutica de las afecciones que le corresponden como especialista y una vez concluido el estudio se encarga del seguimiento yio revisión.

Objetivos: Prestar atención a los casos hospitalizados y realizar estudio para determinar enfermedades.

Proveedores: Abastecimiento General, Cocina- Comedor, Vestuario, Lavandería, Central de Esterilización, Laboratorio Fitofármacos, Electromedicina, Medios diagnóstic 08 , Mantenimiento, Servicios Generales, P atolo gía, Farmacia.

Clientes Pacientes ingresados y acompañantes, pacientes de consulta externa, sery icio de urgencias, Atención primaria de salud, Policlínicos de: Canimar, Guanábana, Playa, Reparto Reynol Garcia, Reparto 2 de Diciembre y Universidad de Matanzas "Camilo Clenfuegos".

Entradas: pacientes, medicamentos, material e instrumental gastable y estéril, médicos, enfermeras, técnicos, historia clínica, hojas de cargo.

Salidas: Paciente tratado, paciente con tratamiento, Resumen de H. Clínica, Material desechable o no estéril.

Grupos de interés: personal médico y paramédico, proveedores, estudiantes de medicina y técnicos medios, directivos.

Inicio del Proceso: examinar al paciente.

Fin del proceso: dar alta al paciente, trasladar al paciente a otro ho sp tal u otro servicio.

Actividades incluidas: recibir al paciente por el médico, registrar el caso en la hoja de cargo, examinar al paciente, orientar tratamiento inicial esperar por los resultados, dar orden de ingre so, cumplir las indicaciones médicas por la enfermera en sala, plasmar la evolución del caso en la historia clínica, esperar la recuperación del paciente, dar alta o remisión médica al paciente.

Procedimientos: protoc olos clínico-terapéutic os

Indicadores: promedio de camas, mortalidad, correlación IngresosiEgresos satisfacción de paciente, indice ocupacional, indice de ausentismo, promedio estadia índice de rotación, intervalo de sustitución, índice de reingreso, tasa de infecciones.

Variables de control: dias camas, dias pacientes, costos unitarios, ingresos, egresos, fallecidos Registros: historias clínic as, registros de infecciones, registros de pacientes, registro de complementarios, libro de entrega de guardia, actas de discusiones de casos complejos, manual de indicadores.

Inspecciones: auditoría mensual y semestral, control de enfermería, circulo de calidad, vigilancia epidemiológica

Procesos relacionados: Medios Diagnósticos, Abastecimiento de Material, Áseguramiento Técnico, Gestión del Conocimiento, Gestión de la Calidad, Consulta Externa, Urgencia y Emergencia

Actividades relacionadas con otros procesos: recibir al paciente (urgente o electivo), indicar pruebas diagnósticas, orientar exámenes complementarios, confeccionar historia clínica para dar seguimiento por consulta externa.

\section{seguimiento porconsulta externa.}

Figura 5. Ficha del PROCESO MEdicina INTERNa 
Así se determinó, por un lado, que el $21 \%$ de las actividades poseen un aporte de valor débil, el $44 \%$ medio y el $35 \%$ fuerte; por otro lado, que la contribución específica a cada criterio denotó que se debe trabajar en la alineación del proceso y sus actividades a los objetivos estratégicos y a las características de calidad; y finalmente, que es preciso estudiar posibilidades de mejoramiento en cuanto a los tiempos de operación, la gestión basada en las características clínicas de los pacientes, la prevención basada en los riesgos y el nivel de servicio al paciente y los acompañantes.

La caracterización de la casuística del proceso, a partir del muestreo de historias clínicas correspondientes a los años 2004 y 2005, permitió conformar las categorías diagnósticas mayores (CDM) y valorar el porcentaje de pacientes que se hospitalizaron de acuerdo a igual diagnóstico. La tabla 2 refleja los principales grupos de pacientes según la frecuencia de ingresos y el total de días-cama utilizados en el periodo evaluado, lo que da una idea del volumen de recursos generados y la necesidad de estudiar las secuencias de actividades involucradas en su atención.

TABLA 2. CDM CON MAYORES DÍAS-CAMA

\begin{tabular}{|l|c|c|}
\hline \multirow{2}{*}{$\begin{array}{l}\text { Categoría diagnóstica } \\
\text { mayor }\end{array}$} & \multicolumn{2}{|c|}{ Días-cama } \\
\cline { 2 - 3 } & $\mathbf{2 0 0 4}$ & $\mathbf{2 0 0 5}$ \\
\hline $\begin{array}{l}\text { Enfermedades y } \\
\text { trastornos del sistema } \\
\text { circulatorio }\end{array}$ & 230 & 110 \\
\hline $\begin{array}{l}\text { Enfermedades y } \\
\text { trastornos del sistema } \\
\text { nervioso }\end{array}$ & 99 & 142 \\
\hline $\begin{array}{l}\text { Enfermedades y } \\
\text { trastornos del sistema } \\
\text { respiratorio }\end{array}$ & 142 & 160 \\
\hline $\begin{array}{l}\text { Enfermedades y } \\
\text { trastornos del sistema } \\
\text { digestivo }\end{array}$ & 165 & 127 \\
\hline
\end{tabular}

Fuente: (53)
Mediante el estudio de tiempos, con ayuda de la distribución Beta y el modelado de procesos con la técnica IDEF3, se determinó la duración del ciclo del proceso y la duración total. Así, se identificaron las actividades que más inciden en la duración del ciclo operativo, como es el caso de la confección de la historia clínica, la cual depende de su extracción de registros o admisión y de plasmar la información con los resultados del examen físico, la entrevista al paciente y la entrega de resultados de los complementarios. Entre tanto, el 63\% del ciclo total se distribuye entre los tiempos de espera, las interrupciones y los tiempos de aprovisionamiento.

El análisis de los riesgos asociados a los procesos de atención de estos grupos de pacientes reveló la no oportuna detección de problemas reflejados en la historia clínica, la incorrecta orientación del tratamiento, la innecesaria orientación de estudios diagnósticos, la aparición de síntomas no detectados a tiempo en el paciente durante su evolución, la ocurrencia de infecciones (sepsis urinaria, flebitis) y estrés en el personal. El no completamiento, en determinados periodos, de las historias clínicas trae como consecuencia fallos en el seguimiento a los pacientes hospitalizados, posibles complicaciones o decisiones erróneas, lo cual puede llegar a ser grave, de acuerdo a la complejidad de cada caso.

Con las valoraciones precedentes se evaluó el nivel de servicio a los pacientes, basado en el comportamiento de tres parámetros críticos, derivados de las encuestas de calidad a pacientes y los cuestionarios aplicados al personal asistencial, estos son: fiabilidad de los suministros, tiempos de entrega e información (tabla 3). Entonces, el nivel de servicio alcanzó un valor de $48 \%$, motivado por un comportamiento entre regular y bajo del aseguramiento de los recursos y de los tiempos de entrega, como se percibió previamente. 
Tabla 3. NiVel de SERVicio a PaCientes y aCOMPañantes

\begin{tabular}{|l|c|c|c|c|c|c|c|}
\hline Parámetros & $\begin{array}{c}\text { Peso } \\
\text { relativo }\end{array}$ & $\mathbf{5}$ & $\mathbf{4}$ & $\mathbf{3}$ & $\mathbf{2}$ & $\mathbf{1}$ & Total \\
\hline Fiabilidad de los suministros & 0.3 & & & $\mathbf{x}$ & & & 0.9 \\
\hline Información & 0.4 & & & $\mathbf{x}$ & & & 1.2 \\
\hline Tiempo de entrega del servicio & 0.3 & & & & & $\mathbf{x}$ & 0.3 \\
\hline Total & \multicolumn{7}{|c|}{} \\
\hline Nivel de servicio
\end{tabular}

Fuente: (53)

De manera general, las herramientas aplicadas facilitaron la identificación de insuficiencias en: la organización y el diseño de los procesos y su capacidad operativa; el aporte de valor de las actividades; la gestión de los suministros basada en su impacto en la asistencia médica; la utilización de los recursos (cama hospitalaria, salones quirúrgicos) y de los tiempos; e igualmente destacó la pertinencia de asociar estos análisis a las características clínicas de los pacientes, un aspecto que puede complejizar la gestión de procesos asistenciales.

Cierra esta fase la propuesta de un programa de mejoras, relativas a: la sistematización de métodos clínicos y protocolos terapéuticos; la transferencia de buenas prácticas internas y externas; el diseño de sistemas de programación de salones quirúrgicos y distribución de materiales médicos y no médicos, con base en la coordinación entre los procesos de apoyo y los servicios asistenciales; la reducción de los tiempos de entrega mediante la eliminación de actividades que no aportan valor y la automatización de otras de gran aporte; la gestión preventiva basada en riesgos y el diseño de puntos críticos de control, junto a potenciar la medición del desempeño hospitalario, haciendo uso de un sistema de indicadores clave.

78 Fase IV. Seguimiento y control. Diseño del índice integral de desempeño de los procesos hospitalarios. Como parte del sistema de seguimiento y control se diseña un índice integral que engloba un número significativo de indicadores que miden eficacia, eficiencia y calidad de los procesos hospitalarios. Los pasos para su diseño son:

1. Selección de indicadores. Se consultaron fuentes bibliográficas que exploran aspectos relacionados con los indicadores hospitalarios, aparejado al análisis de aquellos referidos como fundamentales en las organizaciones estudiadas.

Este listado se redujo por medio del método Delphi (tabla 4), aplicado a expertos seleccionados en estas instalaciones, para obtener seis indicadores que dichos expertos coincidieron en que son útiles y ampliamente utilizados en la gestión hospitalaria: estadía hospitalaria, índice ocupacional, tasa de infecciones intrahospitalarias, índice de positividad de los medios diagnósticos, índice de operaciones suspendidas y mortalidad neta. Para el caso específico del proceso quirúrgico del hospital general resultaron los indicadores: rendimiento quirúrgico por salón; estadía preoperatoria; índice de reintervenciones; índice de operaciones suspendidas, y operaciones por especialista quirúrgico.

2. Estimación de su peso relativo. Para estimar el peso relativo de los indica- 
TABLA 4. IDENTIFICACIÓN DE EXPERTOS POR HOSPITAL

\begin{tabular}{|l|l|l|l|l|}
\hline \multicolumn{2}{|l|}{ Expertos /hospital/coeficiente de experticia } & \\
\hline $\begin{array}{l}\text { Clínico-quirúr- } \\
\text { gico 1 }\end{array}$ & Provincial & Ginecobstétrico & $\begin{array}{l}\text { Clínico-quirúr- } \\
\text { gico 2 }\end{array}$ & Hospital general \\
\hline Experto $1 / 0.91$ & Experto $1 / 0.89$ & Experto /0.93 & Experto $1 / 0.87$ & Experto $1 / 0.95$ \\
\hline Experto 2/0.93 & Experto $2 / 0.84$ & & Experto 2/0.89 & Experto 2/0.72 \\
\hline Experto 3/0.91 & Experto 3/0.93 & & Experto 3/0.93 & Experto 3/1 \\
\hline Experto 4/0.86 & Experto 4/0.91 & & Experto 4/1 & Experto 4/1 \\
\hline Experto 5/0.81 & Experto 5/0.88 & & Experto 5/0.80 & Experto 5/0.75 \\
\hline Experto 6/0.80 & Experto 6/0.98 & & Experto 6/1 & Experto 6/1 \\
\hline Experto 7/0.89 & Experto 7/0.87 & & Experto 7/0.92 & Experto 7/0.87 \\
\hline & & & Experto 8/1 & \\
\hline & & & Experto 9/0.92 & \\
\hline
\end{tabular}

Fuente: (53) y (55)

dores se utilizó el método $\mathrm{AHP}^{2}$ y se obtuvo que la estadía hospitalaria, el índice ocupacional y la tasa de infección intrahospitalaria poseen los pesos mayores. Esto se debe a que son los más utilizados en la gestión del día a día en las organizaciones hospitalarias.

3. Confección del índice integral. Para el cálculo del índice integral se desarrolló la expresión (1), que muestra una comparación entre el máximo nivel que puede ser alcanzado (en el caso de que todos los indicadores obtengan la más alta puntuación), y el que posee cada indicador de acuerdo a su comportamiento real.

$$
\text { IDhosp }=\frac{\sum_{j=1}^{Q} P j * V j}{5 \sum_{i}^{Q} V_{j}}
$$

2 Un número creciente de investigaciones utiliza este método para otorgar un peso relativo a los indicadores de los índices integrales propuestos.
Donde:

IDhosp: índice integral de desempeño de los procesos hospitalarios.

$P j$ : puntuación del indicador j-ésimo.

$V j$ : peso relativo del indicador j-ésimo.

$Q$ : cantidad de indicadores que se integran al índice.

4. Determinación de la forma de evaluación. La escala utilizada es de 1 a 5 , tomando la tendencia de los indicadores precedentes estudiados. Para el caso de indicadores como la mortalidad, para valores muy elevados la puntuación otorgada es cero.

Para normalizar la evaluación de los indicadores se describe el valor deseado (propósito), los rangos para cada propósito y la puntuación que se otorga de acuerdo a dicho rango en la escala utilizada. De esta forma se describe el comportamiento de los indicadores para cuatro hospitales (tabla 5). 


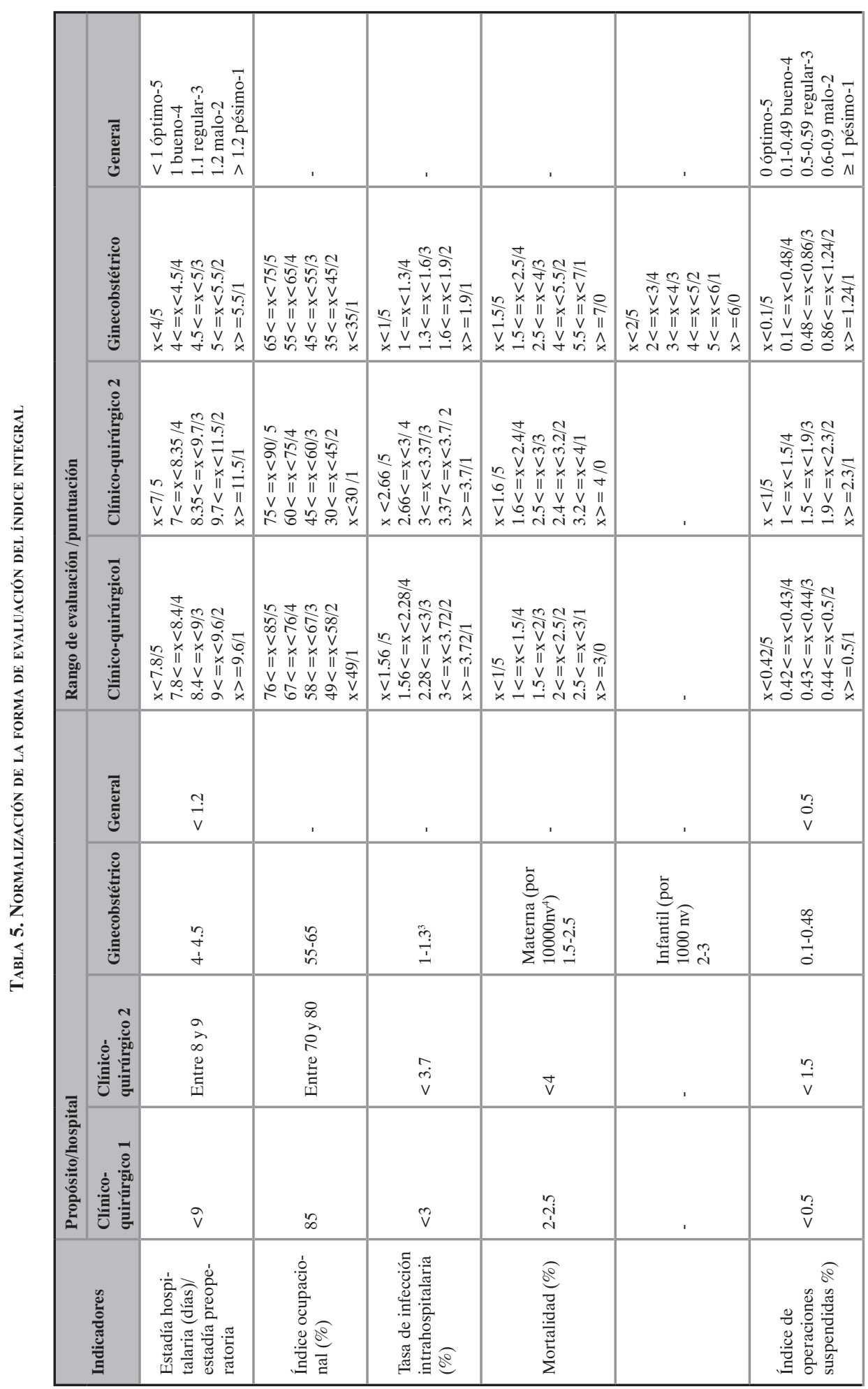




\begin{tabular}{|c|c|c|c|c|c|}
\hline & 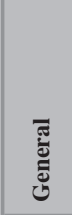 & ' & 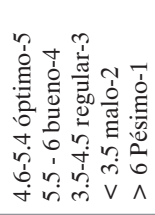 & 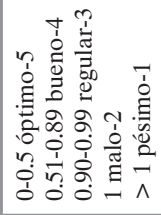 & 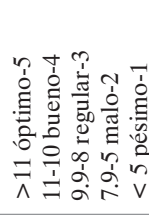 \\
\hline & 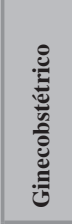 & 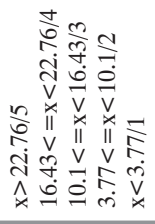 & & & \\
\hline 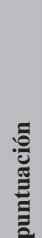 & 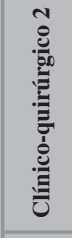 & 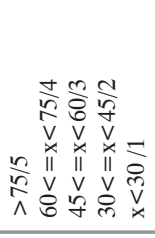 & & & \\
\hline 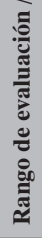 & 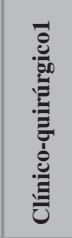 & 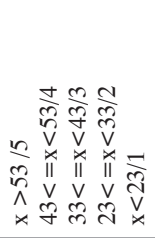 & & & \\
\hline \multirow{4}{*}{ 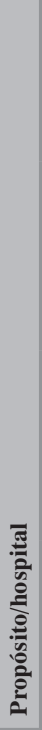 } & 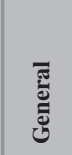 & & $\begin{array}{l}0 \\
\mathrm{VI} \\
\because \\
+ \\
\wedge\end{array}$ & 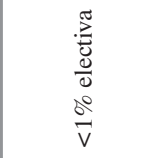 & \multirow[t]{2}{*}{$\exists$} \\
\hline & 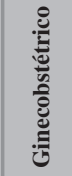 & 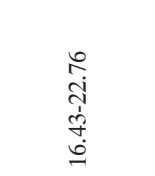 & & & \\
\hline & 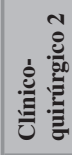 & $\begin{array}{l}\stackrel{0}{1} \\
\end{array}$ & & & \\
\hline & 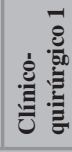 & 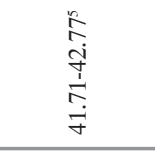 & & & \\
\hline & 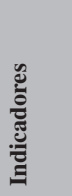 & 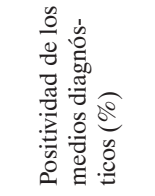 & 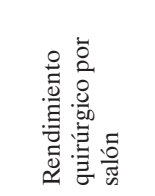 & 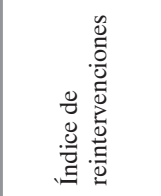 & 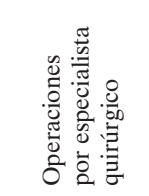 \\
\hline
\end{tabular}

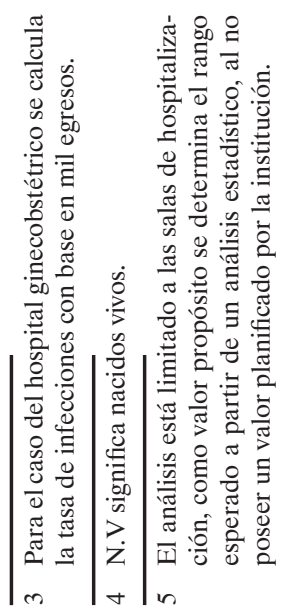


5. Escala de evaluación del índice integral. Para una primera aproximación, los análisis del comportamiento del índice se harán de acuerdo a una escala donde se considerará excelente para 0.80-1.00, buena para $0.60-0.80$, regular para 0.40 0.60, mala $0.20-0.40$ y pésima $0.00-0.20$.

La concepción de este índice se produjo de forma paralela a las etapas iniciales de introducción de la gestión por procesos, para luego constituirse en una herramienta con carácter dual en el procedimiento metodológico empleado, pues, a la vez que se utiliza en la retroalimentación y control en esta fase, su medición puede ser el punto de partida en el diagnóstico de la organización (fase I).

Su evaluación en los principales hospitales estudiados revela y comprueba dificultades que pueden generalizarse como referentes a la calidad de la atención y la eficiencia operativa de los procesos asistenciales y clínicos estudiados, de acuerdo al estudio de la dinámica de indicadores como la estadía hospitalaria, la mortalidad, el índice de reintervenciones, el índice de operaciones suspendidas y el rendimiento quirúrgico por salón (tabla 6).

Tabla 6. Situación INICIAL del DESEMPEÑo de LOS PROCESOS EN CUATRO HOSPITALES MATANCEROS

\begin{tabular}{|c|c|c|c|c|c|}
\hline \multirow[b]{2}{*}{ Indicadores/hospital } & \multirow[b]{2}{*}{$\begin{array}{c}\text { Peso } \\
\text { relativo } \\
(\mathbf{V j})\end{array}$} & \multicolumn{3}{|c|}{ Puntuación } & \multirow[b]{2}{*}{ General } \\
\hline & & $\begin{array}{c}\text { Clínico- } \\
\text { quirúrgico } 1\end{array}$ & Ginecobstétrico & $\begin{array}{c}\text { Clínico } \\
\text { quirúrgico } 2\end{array}$ & \\
\hline Estadía hospitalaria (días) & 0.41 & 2 & 3 & 2 & - \\
\hline $\begin{array}{l}\text { Estadía preoperatoria } \\
\text { (días) }\end{array}$ & 0.08 & - & - & - & 3 \\
\hline Índice ocupacional $(\%)$ & 0.23 & 3 & 3 & 3 & - \\
\hline $\begin{array}{l}\text { Tasa de infección } \\
\text { intrahospitalaria }(\%)\end{array}$ & 0.14 & 5 & 3 & 5 & - \\
\hline Mortalidad (\%) & 0.1 & 3 & 2 & 0 & - \\
\hline $\begin{array}{l}\text { Índice de operaciones } \\
\text { suspendidas }(\%)\end{array}$ & 0.05 & 5 & 4 & 4 & \\
\hline $\begin{array}{l}\text { Índice de operaciones } \\
\text { suspendidas proceso } \\
\text { quirúrgico }(\%)\end{array}$ & 0.28 & - & - & - & 1 \\
\hline $\begin{array}{l}\text { Positividad de los medios } \\
\text { diagnósticos }(\%)\end{array}$ & 0.07 & 3 & 3 & 5 & - \\
\hline $\begin{array}{l}\text { Rendimiento quirúrgico } \\
\text { por salón }\end{array}$ & 0.2 & - & - & - & 2 \\
\hline Índice de reintervenciones & 0.2 & - & - & - & 1 \\
\hline $\begin{array}{l}\text { Operaciones por } \\
\text { especialista quirúrgico }\end{array}$ & 0.42 & - & - & - & 4 \\
\hline IDhosp & & $59.4 \%$ & $60 \%$ & $55.2 \%$ & $48.99 \%$ \\
\hline
\end{tabular}

Fuente: (53) y (55) 


\section{Evaluación de los resultados alcanzados}

Para la evaluación del nivel alcanzado, una vez puesto en práctica un núcleo importante de mejoras, se realizaron mediciones a nivel de organización y procesos y se contrastaron con la situación delineada en el diagnóstico inicial, para así comprobar la eficacia de las propues- tas de mejora y su impacto en el desempeño de los procesos y en la gestión hospitalaria.

Como es visible en la tabla 7 , los niveles de satisfacción de los pacientes y acompañantes muestran un incremento, a la vez que aumenta el rigor en la aplicación de los instrumentos de evaluación, y la mejora en el nivel de

Tabla 7. Evaluación de los Resultados alCaNZados EN EL NIVEL de SERVICIO Y EL DESEMPEÑo de LOS PROCESOS

\begin{tabular}{|c|c|c|c|c|}
\hline \multirow[b]{2}{*}{ Hospitales } & \multirow[b]{2}{*}{ Aspecto } & \multicolumn{2}{|c|}{ Mejora } & \multirow[b]{2}{*}{$\begin{array}{c}\text { Incremento o } \\
\text { disminución } \\
(\%)\end{array}$} \\
\hline & & Antes & Después & \\
\hline \multirow{12}{*}{$\begin{array}{l}\text { Clínico- } \\
\text { quirúrgicos }\end{array}$} & \multicolumn{3}{|l|}{ Servicio ofrecido al paciente y acompañantes } & \\
\hline & \multirow{4}{*}{$\begin{array}{l}\text { Nivel de servicio general }(\%) \\
\text { Eficiencia en el tiempo de entrega (porcentaje del } \\
\text { tiempo total de estancia) } \\
\text { Fiabilidad de los suministros (porcentaje en } \\
\text { tiempo, calidad y cantidad) } \\
\text { Grado de satisfacción de pacientes y } \\
\text { acompañantes }(\%)\end{array}$} & 38 & 60 & 22 \\
\hline & & 37.14 & 41 & 3.86 \\
\hline & & 50 & 83 & 33 \\
\hline & & 97.4 & 99.2 & 1.8 \\
\hline & \multicolumn{3}{|l|}{ Comportamiento de los procesos } & \\
\hline & $\begin{array}{l}\text { Índice de desempeño de los procesos (IDhosp) } \\
(\%)\end{array}$ & 66.8 & 79.8 & 23 \\
\hline & \multirow{4}{*}{$\begin{array}{l}\text { Estadía (días) } \\
\text { Índice ocupacional }(\%) \\
\text { Tasa de infecciones intrahospitalarias }(\%) \\
\text { Índice de positividad de los medios diagnósticos } \\
(\%)\end{array}$} & 9 & 8.2 & 8.9 \\
\hline & & 65.50 & 72.8 & 7.3 \\
\hline & & 1.5 & 1.4 & 0.1 \\
\hline & & 41.2 & 45.8 & 4.6 \\
\hline & $\begin{array}{l}\text { Dinámica de arribo de pacientes (pacientes por } \\
\text { año) }\end{array}$ & 59896 & 60631 & 1.22 \\
\hline \multirow{11}{*}{$\begin{array}{l}\text { Hogar de } \\
\text { ancianos }\end{array}$} & \multicolumn{3}{|l|}{ Servicio ofrecido al adulto mayor y a sus familiares } & \\
\hline & Nivel de servicio general $(\%)$ & 38 & 86 & 48 \\
\hline & Eficiencia en el tiempo de entrega $(\%)$ & 65.21 & 92.78 & 27.57 \\
\hline & $\begin{array}{l}\text { Nivel de actividad (cantidad de pacientes } \\
\text { atendidos días/paciente) }\end{array}$ & 39055 & 44165 & 13.1 \\
\hline & Calidad en la información (\%) & 75 & 90 & 15 \\
\hline & Fiabilidad en entrega de insumos (\%) & 70 & 91 & 21 \\
\hline & \multicolumn{3}{|l|}{ Calidad de vida } & \\
\hline & Mortalidad (\%) & 28.4 & 24 & 4.4 \\
\hline & $\begin{array}{l}\text { Porcentaje de pacientes con estancia de más de } \\
\text { un año }\end{array}$ & 14.28 & 57.8 & 43.68 \\
\hline & Casos de ancianos con escabiosis & 139 & 104 & 25.2 \\
\hline & Casos de ancianos con micosis & 42 & 21 & 50 \\
\hline
\end{tabular}

Fuente: elaboración propia 


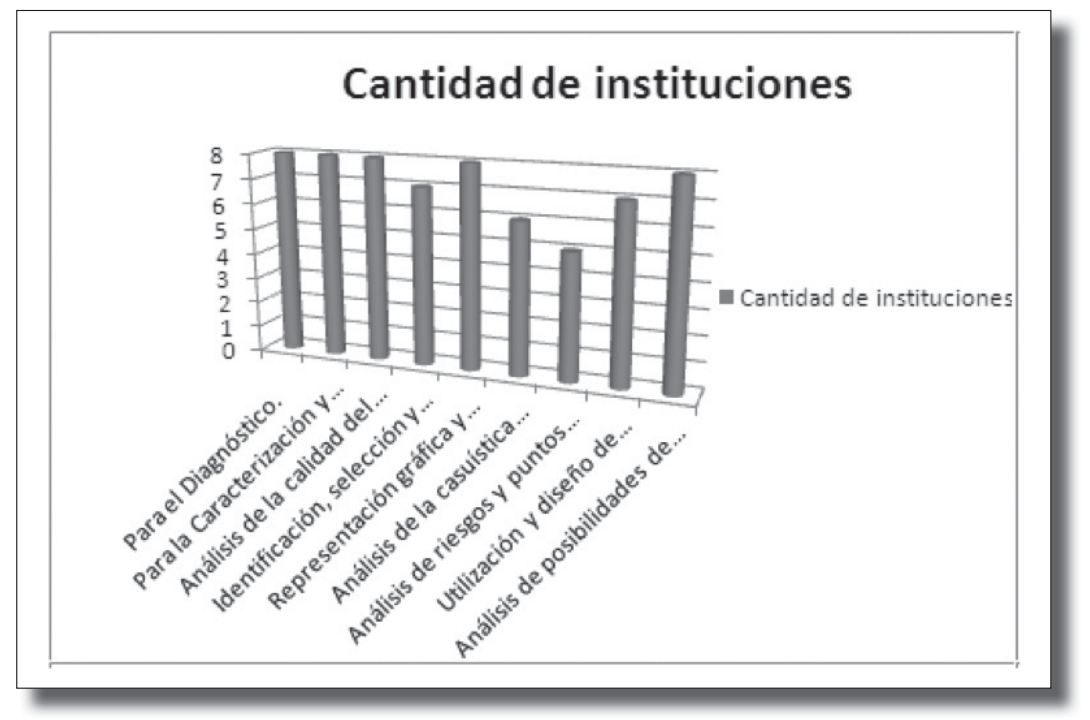

Figura 6. Generalización de los Resultados en CENTros de SAlud Matanceros

Fuente: elaboración propia

servicio del proceso se constata a través del comportamiento de sus parámetros.

La extensión del procedimiento y las herramientas propuestas a otras organizaciones demuestra su factibilidad y posibilidad de generalización; entonces, este ha sido aplicado total o parcialmente en ocho instituciones hospitalarias (figura 6).

\section{Discusión}

El procedimiento para incorporar la gestión por procesos en instalaciones hospitalarias tiene como principal característica la integración de diversas herramientas y métodos de utilidad en la caracterización, el diagnóstico, la mejora y el control, además de su flexibilidad de utilización. Precisamente, la clasificación de las instituciones de salud reveló que, de manera análoga a los procesos industriales, existe intermitencia en las actividades, pues su ejecución responde a las complejidades clínicas de los pacientes; lo que conlleva conferirle gran importancia a estudiar los tipos de pacientes que arriban o se alojan en el hospital, por cuanto esto define secuencias de tratamiento y consumo de recursos, entre otros aspectos de la gestión.

El uso de un índice integral posibilitó: la evaluación de la gestión de los procesos hospitalarios para un número reducido y relevante de indicadores; la comparación entre diferentes procesos internos similares y hospitales de igual perfil; la búsqueda de oportunidades de mejora, vía el análisis de los inductores de actuación y su relación con los procesos donde se origina la desviación; y el análisis de la efectividad de las soluciones implementadas y proyectadas.

En cuanto a las brechas detectadas a partir de la descripción de los procesos, la evaluación de entradas y proveedores, el análisis de valor añadido y de la casuística hospitalaria responden a dedicar esfuerzos en la organización y al diseño de los procesos y su capacidad operativa, la mejora en el aporte de valor, la gestión de los suministros basada en su impacto en la asistencia médica y la reducción de los tiempos. Por último, se lograron avances en la gestión, refle- 
jados en el comportamiento del índice integral de desempeño de los procesos hospitalarios (IDhosp) y el nivel de servicio, antes y después de aplicados los instrumentos propuestos para los hospitales clínico-quirúrgicos, en tanto para el hogar de ancianos se constata dicho progreso a través del nivel de servicio y otros indicadores más específicos y propios de su actividad; lo anterior motivó la generalización de los resultados a otras instituciones para demostrar así la viabilidad de los instrumentos en la mejora del desempeño hospitalario.

\section{Conclusiones}

El estudio de varios procedimientos para la gestión por procesos, elaborados por autores nacionales e internacionales, revela la existencia de un grupo de herramientas útiles para potenciar el perfeccionamiento de los procesos, las cuales constituyen actualmente buenas prácticas en la gestión empresarial.

En Cuba los servicios de salud demandan la introducción de estas herramientas en sus sistemas de gestión, tal y como lo plantea el Sistema de Salud en sus proyecciones de trabajar por la excelencia en los servicios.

La aplicación de un grupo de estas herramientas en instituciones hospitalarias matanceras, asociadas a un procedimiento para la inserción de la gestión por procesos refleja, en los resultados obtenidos, su utilidad y pertinencia para la mejora de los procesos hospitalarios y su contribución, por ende, a la calidad del servicio que ellas brindan.

\section{Referencias}

1. Organización Mundial de la Salud (OMS). Estadísticas sanitarias mundiales. Washington: OMC; 2009.

2. Bonafont X, Casasín T. Protocolos terapéuticos y vías clínicas. Farmacia Hospitalaria. 2004; 28(6):82-100.
3. Claveranne JP, Pascal C. Repenser les processus a l'hopital. Une methode au service de la performance París: Medica Editions; 2004.

4. Equiza Escudero JJ. Gestión hospitalaria: nuevas tendencias. Revista Valenciana de Estudios Autonómicos. 1999; (28):31-40.

5. Roth AV, van Dierdonck R. Hospital resource planning: Concepts, feasibility, and framework. Production and Operations Management. 1995; 4:2-29.

6. Butler TW, Leong GK, Everett LN. The operations management role in hospital strategic planning. Journal of Operations Management. 1996; 14:137-56.

7. Langabeer Ii JR. Health care operations management: A quantitative approach to business and logistics. University of Texas School of Public Health; 2008.

8. Rechel B, Wright S, Barlow J, Mckee M. Planificación de la capacidad hospitalaria: desde la medición de existencias hasta el modelado de flujos. Boletín de la Organización Mundial de la Salud. 2012.

9. Acosta Chávez M. El hospital en el siglo XXI. Revista Horizonte Médico. 2008; 8(2):56-9.

10. Hsieh NC, Lee KC, Chen W. The transformation of surgery patient care with a clinical research information system. Expert Systems with Applications. 2013; (40):211-21.

11. Ruiz Iglesias L. ¿A qué nos referimos cuando hablamos de gestión clínica? Investigación Clínica y Farmacéutica. 2004; 1(4):24-34.

12. Hsieh NC, Lee KC, Chen W. The transformation of surgery patient care with a clinical research information system. Expert Systems with Applications. 2013; 40:211-21.

13. Vergeles Blanca JM. La gestión de riesgos sanitarios y seguridad del paciente en atención primaria de salud. $9^{\circ}$ Congreso Nacional de la Asociación Española de Gestión de Riesgos Sanitarios. Salamanca, España, 2006.

14. Vitaller Burillo J. El contexto de la gestión de riesgos de la asistencia sanitaria Revista de Calidad Asistencial. 2005; 20(2): 51-52.

15. Carrada Bravo T. Benhmarking y los grupos relacionados con el diagnóstico hospitalario. Rev Med IMSS. 2002; 40(1):25-33.

16. Gómez Jiménez J, Faura J, Burgues L, Pamies S. Gestión clínica de un servicio de urgencias hospitalario: indicadores de calidad, benchmarking y análisis de la casuística (Case-Mix). Gestión Hospitalaria. 2004; 15(1): 3-12.

17. Evers L, van Oostrum JM, Wagelmans APM. Levelled bed occupancy and controlled waiting lists using master surgical schedules [Internet]. 2010. Disponible en: http://hdl.handle.net/1765/21241

18. Quiros Moratos T, Cuesta Peredo D. Sistemas de información en las instituciones sanitarias. Una visión operativa. 2005.Curso experto en Economía de la Salud, Palma de Mayorca, España [Internet]. Disponible en: http://www.informedica.org.ar/pdf/ sadio/2/cheguhem-esp.PDF

19. Carnero Gómez R, Rodríguez Barrios JM. Impacto de los grupos relacionados por el diagnóstico en los 
"Medical devices". Economía de la Salud. 2008; 5(4):216-22.

20. Gemmel P, Vandaele D, Tambeur W. Hospital process orientation (HPO): The development of a measurement tool. Total Quality Management. 2008; 19 (12):1207-17.

21. Spanyi A. More for less: The power of process management. Tampa, Florida: Meghan-Kiffer Press; 2008.

22. Harmon $\mathrm{P}$, Wolf $\mathrm{C}$. The state of business process management. BPTrends; 2010.Duke University, Estados Unidos.

23. Smith H, Fingar P. Business process management - the third wave. Tampa, Florida: Meghan-Kiffer Press; 2003.

24. Deming WE. Quality, productivity, and competitive position. Cambridge, MA: MIT Center for Advanced Engineering Study; 1982.

25. Hammer M, Champy J. Reengineering the corporation: A manifesto for business revolution. NuevaYork: Harper Business; 1993.

26. Melão N, Pidd M. A conceptual framework for understanding business processes and business process modelling. Information Systems Journal. 2000; 10 (2):105-29.

27. Krafzig D, Banke K, Slama D. Enterprise SOA: service-oriented architecture best practices. NJ, Estados Unidos: Prentice Hall-PTR; 2005.

28. Hung RY. Business process management as competitive advantage: A review and empirical study. Total Quality Management. 2006; 17(1):21-40.

29. Rosemann M, Vom Brocke J. The six core elements of business process management. En: Handbook on business process management I. Nueva York: Springer; 2015. p. 105-22.

30. Ravesteyn P. A study into the critical success factors when implementing business process management systems. Managing worldwide operations and communications with information technology [Internet]; 2007. p. 1291-3. Disponible en: https://www.researchgate.net/profile/ Pascal_Ravesteyn/publication/46702063A_Study_ into_the_Critical_Success_Factors_when_Implementing_Business_Process_Management_Systems/ links/545a10540cf2 bccc4912ff58.pdf

31. Leu JD, Huang YT. An application of business process method to the clinical efficiency of hospital. Journal of Medical Systems. 2009; 35(34):9-21.

32. Becker J, Fischer R, Janiesch C. Optimizing us health care processes-a case study in business process management. En: AMCIS 2007 Proceedings; 2007.

33. Stephenson C, Bandara W. Enhancing best practices in public health: Using process patterns for business process managemented. En: Proceedings of the 15th European Conference on Information Systems University of St. Gallen; 2007. p. 2123-34.

34. Kolker A. Process modelling of emergency department patient flow: Effect of patient length of stay on ed diversion. J Med Syst. 2008; (32): 389-401.
35. Bertolini M. Business process re-engineering in healthcare management: A case study. Business Process Management Journal. 2011; 17(1):42-66.

36. Scheuerlein H, Rauchfuss F, Dittmar Y, Molle R, Lehmann T, Pienkos N, Settmacher U. New methods for clinical pathways - business process modeling notation (bpmn) and tangible business process modeling (t. Bpm). Langenbeck's Archives of Surgery. 2012; 397(5):755-1.

37. Fernández Sánchez E. Dirección de la producción i. Fundamentos estratégicos. Madrid: Civitas; 1993.

38. Hernández Nariño A, Medina León A, Nogueira Rivera D, Negrín Sosa E, Marqués León M. La caracterización y clasificación de sistemas, un paso necesario en la gestión y mejora de procesos. Particularidades en organizaciones hospitalarias. Dyna. 2014; 81(184):193-200.

39. Schroeder RG. Administración de operaciones. Toma de decisiones en la función de operaciones. México D. F.: McGraw-Hill; 1992.

40. Nogueira Rivera D, Medina León A, Nogueira Rivera C. Fundamentos del control de gestión empresarial. Ciudad de La Habana: Editorial Pueblo y Educación; 2004.

41. Amozarrain M. La gestión por procesos. s.1.: Mondragón; 1999.

42. Saaty T. The analytic hierarchy process. Nueva York: McGraw-Hill; 1981.

43. Trischler WE. Mejora del valor añadido en los procesos. Barcelona: Ediciones Gestión 2000; 1998.

44. Biazzo S, Bernardi G. Process management practices and quality systems standards. Risk and opportunities of the new ISO 9001 certification. Business Process Management Journal. 2003; 9(2):149-69.

45. Hernández Nariño A, Medina León A, Nogueira Rivera D. Influencia de la actividad logística en la gestión de los procesos hospitalarios. Revista Logística Aplicada. 2009; (13).

46. Medina León A, Nogueira Rivera D, Hernández Nariño A, Viteri Moya JR. Relevancia de la gestión por procesos en la planificación estratégica y la mejora continua. Ecuador. Revista Eídos. 2010; 1(2):101-30. Disponible en: http://www.ute.edu.ec/ posgrados/EIDOS2.pdf

47. Hodson WK. Maynard: Manual del ingeniero industrial I, cuarta edición. México: McGrawHill; 2004.

48. Sánchez Lara A. Planificación y control de la producción. Ciudad Habana: Universidad de la Habana, Escuela de Ingeniería Industrial; 1979.

49. Fonseca Hernández M, Rodríguez Buergo D, Peraza Ramos JM, Bonet Collazo O, Vila Díaz J, Jorge Cruz N. Comportamiento de indicadores hospitalarios durante el decenio 1990-1999. Hospital pediátrico universitario "Paquito González Cueto". Revista Cubana de Pediatría. 2001; 73(3):158-64.

50. Segura Sardinas O, Lozano Álvarez E, Guillén Godales T, Herrera Domínguez H. Construcción de un indicador sintético para medir diferencias en los servicios hospitalarios. Correo Científico Médico [Internet]. 2004; 8(1). Disponible en: http://www. cocmed.sld.cu/no81/n81ori2.htm 
51. Frías Jiménez R, González Arias M, Cuétara Sánchez L, Corzo Sánchez Y, González Laucirica A. Herramientas de apoyo a la solución de problemas no estructurados en empresas turísticas (Haspnet). Matanzas, Cuba: Universidad de Matanzas; 2008.

52. Hernández Nariño A. Contribución a la gestión y mejora de procesos en instalaciones hospitalarias del territorio matancero [tesis en opción al grado científico de doctor en Ciencias Técnicas]. Universidad de Matanzas "Camilo Cienfuegos", Facultad Industrial-Economía; 2010-

53. Hernández Nariño A, Nogueira Rivera D, Medina León A, Marqués León M. Inserción de la gestión por procesos en instituciones hospitalarias. Concepción metodológica y práctica. Revista de Administração da Universidade de São Paulo. 2013; 48(4):739-56.
54. Delgado Landa A. Herramientas de la investigación de operaciones para abordar problemas de decisión en el proceso quirúrgico del hospital julio M. Aristegui Villamil [Tesis en opción al título de máster en Administración de Empresas. Mención: Administración de Negocios]. Universidad de Matanzas "Camilo Cienfuegos", Facultad de Ciencias Económicas e Informática; 2013.

55. Nogueira Rivera D. Modelo conceptual y herramientas de apoyo para potenciar el Control de Gestión en las empresas cubanas [tesis en opción al grado científico de doctor en Ciencias Técnicas]. Matanzas, Cuba: Universidad de Matanzas "Camilo Cienfuegos", Facultad Ingeniería IndustrialEconomía; 2002. 